\title{
Strain-Dependent Variation in Acute Ischemic Muscle Injury
}

Cameron A. Schmidt, ${ }^{\dagger \dagger}$ Adam J. Amorese, ${ }^{* \dagger}$ Terence E. Ryan, ${ }^{* \dagger}$ Emma J. Goldberg, ${ }^{* \dagger}$ Michael D. Tarpey, ${ }^{* \dagger}$ Thomas D. Green, ${ }^{* \dagger}$ Reema R. Karnekar, ${ }^{* \dagger}$ Dean J. Yamaguchi, ${ }^{\ddagger \S}$ Espen E. Spangenburg, ${ }^{* \dagger}$ and Joseph M. McClung ${ }^{* \dagger}$

From the Department of Physiology, * Brody School of Medicine, the East Carolina Diabetes and Obesity Institute, ${ }^{\dagger}$ the Department of Cardiovascular Sciences, ${ }^{\ddagger}$ and the Division of Vascular Surgery, ${ }^{\complement}$ East Carolina University, Greenville, North Carolina

Accepted for publication

January 11, 2018.

Address correspondence to Joseph M. McClung, Ph.D., Diabetes and Obesity Institute, Office 4109, Mail Stop 743, East Carolina Heart Institute, Brody School of Medicine at East Carolina University, 115 Heart Dr, Greenville, NC 27834-4354. E-mail: mcclungj@ecu.edu.

\begin{abstract}
Limited efficacy of clinical interventions for peripheral arterial disease necessitates a better understanding of the environmental and genetic determinants of tissue pathology. Existing research has largely ignored the early skeletal muscle injury response during hind limb ischemia (HLI). We compared the hind limb muscle response, after 6 hours of ischemia, in two mouse strains that differ dramatically in their postischemic extended recovery: $\mathrm{C} 57 \mathrm{BL} / 6 \mathrm{~J}$ and $\mathrm{BALB} / \mathrm{CJ}$. Perfusion, measured by laser Doppler and normalized to the control limb, differed only slightly between strains after $\mathrm{HLI}(<12 \%$ across all measures). Similar $(<10 \%)$ effect sizes in lectin-perfused vessel area and no differences in tissue oxygen saturation measured by reflectance spectroscopy were also found. Muscles from both strains were functionally impaired after HLI, but greater muscle necrosis and loss of dystrophin-positive immunostaining were observed in BALB/cJ muscle compared with $\mathrm{C} 57 \mathrm{BL} / 6 \mathrm{~J}$. Muscle cell-specific dystrophin loss and reduced viability were also detected in additional models of ischemia that were independent of residual perfusion differences. Our results indicate that factors other than the completeness of ischemia alone (ie, background genetics) influence the magnitude of acute ischemic muscle injury. These findings may have implications for future development of therapeutic interventions for limb ischemia and for understanding the phasic etiology of chronic and acute ischemic muscle pathophysiology. (Am J Pathol 2018, 188: 1246-1262; https://doi.org/10.1016/j.ajpath.2018.01.008)
\end{abstract}

Pathologic limb ischemia occurs as a result of either a chronic disease process or a sudden and immediate blockage of blood flow. Although the immediate loss of blood flow to the limb because of embolism differs from chronic peripheral arterial disease (PAD) by its acute nature, activity-induced transient ischemia is gaining recognition as a significant contributor to PAD pathology. ${ }^{1}$ Both cases of ischemia can be devastating to the underlying muscle tissue, resulting in irreversible changes within hours that ultimately lead to myopathy or necrosis. ${ }^{2,3}$ Preclinical rodent models of hind limb ischemia (HLI) have been used for decades to simulate PAD patho$\operatorname{logy} .^{4-6}$ Inbred strains of mice are useful in elucidating genetic contributions to postischemic injury outcomes and serve as a practical platform for preclinical testing of therapeutics. $^{7-15} \mathrm{C} 57 \mathrm{BL} / 6 \mathrm{~J}$ (C57) mice experience a rapid postischemic perfusion recovery concomitant with recovery of limb muscle function. BALB/cJ (B/c) mice experience poor perfusion recovery, superficial tissue necrosis, and poor functional recovery during both acute and subacute hind limb ischemia. ${ }^{5,13}$ Investigators comparing ischemic outcomes in these mice typically differ in their attribution of tissue pathology to impairments in one of a few distinct processes: preexisting vascular anatomy, ${ }^{16-19}$ capacity for postischemic vascular remodeling, ${ }^{5,6,20-22}$ or inherent tissue regenerative potential. $^{23-26}$ Several recent studies have indicated that ischemic outcomes in $\mathrm{B} / \mathrm{c}$ mice can be enhanced by expression of exogenous genes or gene variants associated with the improved phenotypic outcomes in C57 mice. ${ }^{10,27,28}$ These studies have focused on tissue outcomes measured days to weeks after the initial onset of ischemia, however, and have not addressed the contribution of background strain to the immediate ischemic injury sustained in these mice.

Supported by NIH grants R01HL125695 (J.M.M.), R01AR066660 (E.E.S), and F32HL129632 (T.E.R.).

Disclosures: None declared. 
HLI initiates a myodegenerative response in the muscle, resulting in the development of myofiber necrosis within only a few hours after induction. ${ }^{29}$ Myodegeneration is then followed by a complex myoregenerative phase involving clearance of the necrotic tissue by the immune system (approximately 3 to 7 days postinjury) and the formation of new mature myofibers through a process that resembles embryonic myogenesis (approximately 7 to 56 days postinjury). ${ }^{30,31}$ HLI also induces necrosis in affected vascular beds, and as such, regeneration of the limb vasculature is intimately related with the myoregenerative timeline. ${ }^{32}$ Revascularization occurs primarily through two independent processes: angiogenesis, the formation of new capillaries from existing vascular beds; and arteriogenesis, the expansion of the number and the conducting capacity of collateral arteries. ${ }^{5}$ Perfusion recovery curves are consistent among independent studies and involve a slow, linear, and incomplete recovery in $\mathrm{B} / \mathrm{c}$ mice compared with a rapid, nonlinear, full recovery in C57 mice on a timescale of days to weeks. ${ }^{11,13,17,33}$ The delayed recovery timeline in $\mathrm{B} / \mathrm{c}$ mice has generally been attributed to comparatively fewer preexisting collateral feed arteries and interarteriolar network connections, leading to a more severe initial ischemic insult and impaired perfusion recovery. ${ }^{17,20}$ Findings from other studies suggest that C57 and B/c mice have temporally distinct revascularization responses, with $\mathrm{B} / \mathrm{c}$ mice experiencing rapid capillary expansion within days of HLI, and C57 mice experiencing less capillary expansion in lieu of superior compensation from collateral arteries. $^{5,18}$ In recent studies using ameroid constrictor-induced subacute limb ischemia in these strains, more severe skeletal muscle pathology is observed after 7 days of ischemia in $\mathrm{B} / \mathrm{c}$ mice, despite both strains having a matched partial reduction in perfusion and tissue oxygen saturation. ${ }^{13,33}$ This raises the intriguing possibility that the observed differences in recovery timeline between these strains are more closely interrelated with the degree of early muscle tissue pathology than has previously been given consideration, and may result from a strain-dependent skeletal muscle tissue sensitivity to ischemic injury.

Herein, we tested the hypothesis that the acute injury response of $\mathrm{B} / \mathrm{c}$ limb muscle would be more severe than that of C57 mice in response to the same or similar degree of occlusive burden. A short (6 hours) insult of HLI was used to assess whether any immediate differences in blood flow existed between the strains as a result of differences in vascular anatomy, and whether the level of muscle tissue necrosis would be influenced by strain at such an early time point. The degree of reduction in limb perfusion differed only slightly between strains, but $\mathrm{B} / \mathrm{c}$ mice experienced extensive muscle tissue damage compared with C57 mice. These differences were observed at 3 hours, but not at 6 hours, post-mortem in mice euthanized by cervical dislocation (a model that simulates ischemia in the complete absence of residual flow). The muscle response to acute HLI was also assessed in two additional strains of mice known to have similarly distinct anatomical differences in preexisting vascular anatomy: A/J (B/c like) and 129S1/SvImJ (129S; C57 like). Similar dramatic muscle injury was not observed in $\mathrm{A} / \mathrm{J}$ mice, despite complete perfusion reduction, suggesting that $\mathrm{B} / \mathrm{c}$ mice may be unique in this regard. This study will provide a foundation for future studies that aim to uncouple the contribution of protective genetic factors to the myodegenerative phase of ischemic muscle injury, which may have significant implications for the design of novel therapeutics for the treatment and prevention of acute and chronic ischemic injury in PAD patients.

\section{Materials and Methods}

\section{Animals}

Experiments were conducted on adult male (12- to 16-week-old) C57BL/6J $(n=34), \mathrm{BALB} / \mathrm{cJ}(n=32), \mathrm{A} / \mathrm{J}$ $(n=8)$, or $129 \mathrm{~S}(n=8)$ male mice obtained from Jackson Laboratories (Bar Harbor, ME). All work was approved by the Institutional Review Committee of East Carolina University (Greenville, NC). Animal care was in compliance with the Guide for the Care and Use of Laboratory Animals, ${ }^{34}$ Institute of Laboratory Animal Resources, Commission on Life Sciences, National Research Council.

\section{Model of Acute Hind Limb Ischemia}

Acute (terminal) unilateral hind limb ischemia (HLI) was induced, as previously described. ${ }^{11}$ Briefly, mice were anesthetized by i.p. injection of $90 \mathrm{mg} / \mathrm{kg}$ body weight ketamine and $10 \mathrm{mg} / \mathrm{kg}$ xylazine. A small $(<3-\mathrm{mm})$ incision was made between the left inguinal fat pad and the peritoneum. The femoral artery was carefully isolated from the femoral vein in the region distal to the inguinal ligament and proximal to the lateral circumflex branch of the femoral artery (Supplemental Figure S1). Two ligatures were placed at each end of the isolated region, and the femoral artery was transected between them. Mice were administered s.c. $0.5 \mathrm{mg} / \mathrm{kg}$ buprenorphine for pain management during recovery. An experienced surgeon (C.A.S.) performed all surgeries for this study to minimize technical variation. Surgeries were performed within the first 2 hours of the animals' 12-hour light cycle. All animals had free access to food and water before surgeries and during perioperative recovery. Body temperature of approximately $37^{\circ} \mathrm{C}$ was maintained during recovery using a heated circulating water pad. Mice were sacrificed by cervical dislocation under ketamine/xylazine anesthesia 6 hours after ligation.

\section{Postmortem Analysis of Muscle Tissue}

To simulate the effects of ischemia in the complete absence of residual flow, mice were euthanized by cervical dislocation under deep anesthesia and kept at $37^{\circ} \mathrm{C}$ on a heated water mat under a gauze cover. Tissue was then collected 
unilaterally at 3 and 6 hours postmortem for cryosectioning and staining.

\section{Blood Perfusion and Muscle Tissue 0xygen Saturation}

Limb blood flow was measured using laser Doppler perfusion imaging (LDPI), as previously described, ${ }^{11}$ with the following modifications: Animals were placed on a $37^{\circ} \mathrm{C}$ warming pad under ketamine/xylazine anesthesia in a windowless room with controlled lighting. Plantar paws were imaged at a 4 millisecond/pixel scan rate and the medial thigh was imaged at a 10 millisecond/pixel scan rate using a Moor Instruments LDI2-High Resolution System (830 nm) (Moor, Axminster, UK). Hind limb hair was removed with a microshaver (Wahl, Sterling, IL) before scanning. Laser Doppler images were obtained before surgery, immediately after surgery, and after 6 hours of perioperative recovery. Skeletal muscle tissue oxygen saturation (\% oxygen saturation) was assessed using a Moor VMS-OXY white light reflectance spectrometer with a CPT-300 optical probe (Moor Instruments). Under deep anesthesia, the hind limb skin and fascia were carefully removed to reduce noise from off-target light absorption. Stable measurements were taken directly over the surfaces of the vastus lateralis, lateral head of the gastrocnemius, tibialis anterior, and the plantar paw. LDPI and reflectance spectroscopy data were analyzed using the Moor VMS review software version 6.0 .

\section{Postocclusive Reactive Hyperoxia}

Under ketamine/xylazine anesthesia, a small incision was made between the left inguinal fat pad and the abdominal wall. The femoral artery was isolated from the femoral vein in the region distal to the inguinal ligament and proximal to the lateral circumflex branch of the femoral artery. Tissue oxygen saturation measurements (\% oxygen saturation) were obtained at a collection frequency of $10 \mathrm{~Hz}$ using a Moor VMS-OXY white light reflectance spectrometer with a CPT-300 optical probe. Percentage oxygen saturation measurements were made over the vastus medialis muscle during 1 minute of baseline measurement, 3 minutes of temporary occlusion using a 6-0 silk suture, and 3 minutes of reperfusion. Data were analyzed using the Moor VMS review software.

\section{Perfused Vessel Labeling}

Immediately after HLI surgery, $50 \mu \mathrm{L}$ of $1 \mathrm{mg} / \mathrm{mL}$ Griffonia simplicolia isolectin-B ${ }_{4}$ Dylight594 conjugate (Vector Labs, Burlingame, CA) was injected into the left retro-orbital sinus using a 31-gauge needle. Mice were then allowed 6 hours of perioperative recovery before sacrifice. For epifluorescence microscopy in transverse muscle sections, the gastrocnemius muscles were isolated from both the control and ischemic limbs, embedded in OCT medium, and frozen in liquid nitrogen-cooled isopentane for cryosectioning. Sections (10 $\mu \mathrm{m}$ thick) were cut using a CM-3060S cryostat (Leica, Buffalo Grove, IL) and collected on charged glass slides. Sections were then fixed in 1:1 acetone/methanol for 10 minutes at $-20^{\circ} \mathrm{C}$, rehydrated in $1 \times$ phosphate-buffered saline (PBS), and blocked in 5\% goat serum $+1 \times$ PBS for 1 hour at room temperature. Sections were then incubated with goat anti-rat CD31 (platelet endothelial cell adhesion molecule 1) primary antibody at $4^{\circ} \mathrm{C}$ overnight to counterstain for total vessels (1:100 dilution; BioRad, Hercules, CA). Sections were washed $3 \times$ for 10 minutes with cold $1 \times$ PBS and incubated for 1 hour with Alexa-Fluor 488-conjugated anti-rat IgG secondary antibody (1:250; Invitrogen, Carlsbad, CA). Sections were mounted using Vectashield hard mount medium with DAPI for nuclear counterstain (Vector Labs) and imaged with an Evos FL automicroscope (Thermo Fisher, Waltham, MA) with a plan fluorite $20 \times$ coverslip corrected objective lens (numerical aperture $=0.5$, air). The following excitation/emission filter cubes were used: DAPI (357/44-nm excitation; 447/60-nm emission), green fluorescent protein (470/22-nm excitation; 510/42-nm emission), Texas Red (585/29-nm excitation; 624/40-nm emission), and Cy5 (628/ 40-nm excitation; 692/40-nm emission). Images were taken at the anterolateral, central, and ventromedial positions within each muscle section. Image quantification was performed by a blinded investigator (C.A.S.) using ImageJ version 1.5lf (NIH, Bethesda, MD; http://imagej.nih.gov/ij) ${ }^{35}$ by decomposing the images into red/blue/green composites, splitting channels, setting appropriate standard threshold value limits, and measuring the percentage area of Dylight594 (red) and CD31 (green) positive signal within each image. Technical replicates were averaged, and data are represented by mean fluorescence positive area and as a ratio of the ischemic to the control limb.

\section{Muscle Histomorphology}

Tibialis anterior and gastrocnemius muscles from both the ischemic and control limbs (gastrocnemius only for A/J and 129S) were frozen in liquid nitrogen-cooled isopentane in OCT medium. Transverse sections (10 $\mu \mathrm{m}$ thick) were cut using a Leica $3050 \mathrm{~S}$ cryostat and collected on charged slides for staining. Standard methods for hematoxylin and eosin (H\&E) staining were performed, as previously described. ${ }^{11}$ Three images were taken at the anterolateral, central, and ventromedial positions within each tibialis anterior muscle section with an Evos FL autowide field microscope (Life Technologies) with a plan fluorite $20 \times$ coverslip corrected objective lens (numerical aperture $=0.5$, air). Five $(20 \times)$ images in each section were taken at the anterolateral, anteromedial, central, ventrolateral, and ventromedial positions within each gastrocnemius muscle section. Images were analyzed and scored by three independent blinded investigators (A.J.A., T.E.R., E.J.G.). Each image was scored with 0 (not present) or 1 (present) for each of the following parameters: small rounded or basophilic fibers, 
large rounded or acidophilic fibers, apparent necrotic (disintegrated) fibers, expanded interstitial space compared with a typical healthy control, and aggregates of generalized cells in the interstitium. Each $20 \times$ image could receive up to a maximum score of 5, indicating most severe ischemic damage. The median score from all three investigators was obtained, and the scores from each image were totaled to give an aggregate clinical score for each animal. Maximum aggregate score for the tibialis anterior muscle was 15 , and the maximum aggregate score for the gastrocnemius was 25, with higher scores indicating a greater degree of damage.

\section{Muscle Contractile Function}

Contractile force was assessed, as previously described. ${ }^{36}$ Briefly, single extensor digitorum longus and soleus muscles were surgically excised with ligatures at each tendon using a 5-0 silk suture and mounted in an oxygenated bath between a fixed post and force transducer (Aurora 300B-LR; Aurora Scientific, Aurora, ON, Canada) operated in isometric mode. The muscle was maintained in modified Kreb's buffer solution (physiologic saline solution; $\mathrm{pH}$ 7.2) containing 115 $\mathrm{mmol} / \mathrm{L} \mathrm{NaCl}, 2.5 \mathrm{mmol} / \mathrm{L} \mathrm{KCl}, 1.8 \mathrm{mmol} / \mathrm{L} \mathrm{CaCl}{ }_{2}, 2.15$ $\mathrm{mmol} / \mathrm{L} \mathrm{Na}_{2} \mathrm{HPO}_{4}$, and $0.85 \mathrm{mmol} / \mathrm{L} \mathrm{NaH} \mathrm{PO}_{4}$, and main$\begin{array}{lllll}\text { tained at } 25^{\circ} \mathrm{C} \text { under aeration with } 95 \% & \mathrm{O}_{2} / 5 \% & \mathrm{CO}_{2}\end{array}$ throughout the experiment. Resting tension and muscle length were iteratively adjusted for each muscle to obtain the optimal twitch contraction force, and a supramaximal current of $600 \mathrm{~mA}$ was used for stimulation. After a 5-minute equilibration period, isometric tension was evaluated by 200-millisecond pulse trains delivered at 10, 20, 40, 60, 80, 100 , and $120 \mathrm{~Hz}$ (only peak specific force at $120 \mathrm{~Hz}$ shown). Muscle length was determined with a digital microcaliper. Muscles were then trimmed proximal to the suture connections, excess moisture was removed, and wet weights were obtained. The cross-sectional area for each muscle was determined by dividing the mass of the muscle $(\mathrm{g})$ by the product of its length $\left(\mathrm{L}_{0} ; \mathrm{cm}\right)$ and estimated muscle density $\left(1.06 \mathrm{~g} \mathrm{~cm}^{-3}\right)$. Muscle force production was expressed as specific force $\left(\mathrm{N} / \mathrm{cm}^{2}\right)$ determined by dividing the tension $(\mathrm{N})$ by the calculated muscle cross-sectional area.

\section{Cell Viability Assays in Differentiated Primary Myotubes}

Primary myoblast isolation and differentiation was performed, as described previously. ${ }^{11}$ Briefly, hind limb muscles were dissected from 4- to 6-week-old female C57BL/6 or BALB/c mice, digested with pronase $(0.2 \%)$ for 60 minutes at $37^{\circ} \mathrm{C}$, triturated to release precursor cells, and filtered through a 100 $\mu \mathrm{m}$ mesh. Cells were allowed to proliferate to confluence in growth medium (Ham's F10 medium supplemented with 1\% penicillin/streptomycin, $0.2 \%$ amphotericin B, 20\% fetal bovine serum, and $2.5 \mathrm{ng} / \mathrm{mL}$ human fibroblast growth factor). Cells were then preplated for 1 hour on uncoated polystyrene dishes. The supernatant containing myoblasts was transferred into collagen-coated (1 mg/mL in Dulbecco's modified Eagle's medium) plates and grown to confluence. Myoblasts were then propagated in growth medium and used for viability assays within four passages of isolation. Myoblasts were seeded at $8 \times 10^{4}$ cells/well in entactin collagen laminin (Merck Group, Burlington, MA; number 08-110)-coated glass-bottom 96-well plates. Differentiation was induced by serum withdrawal in differentiation medium (Dulbecco's modified Eagle's medium supplemented with $2 \%$ horse serum, $1 \%$ penicillin/streptomycin, $0.2 \%$ amphotericin $\mathrm{B}$, and $0.01 \%$ human insulin/transferrin/selenium). Differentiated myotubes were exposed to 6 hours of hypoxia and nutrient deprivation (HND) by replacing media with Hanks' balanced salt solution and incubating at $37^{\circ} \mathrm{C}$ in a sealed chamber flushed with $95 \%$ nitrogen $/ 5 \% \mathrm{CO}_{2}$. Normoxic controls were incubated at $37^{\circ} \mathrm{C}$ in differentiation media. After treatments, cells were rinsed in PBS and incubated with a $0.25 \times$ solution of resazurin dye (Presto Blue; Thermo Fisher, Waltham, MA) in Hanks' balanced salt solution for 2 hours at $37^{\circ} \mathrm{C}$. Absorbance at 570 and $600 \mathrm{~nm}$ was measured using a Biotek Cytation 5 plate reader (Biotek, Winooski, VT). Viability in each well was calculated by normalizing absorbance at $570 \mathrm{~nm}$ to the reference wavelength $(600 \mathrm{~nm})$ and subtracting the averaged absorbance values from blank (cell-free) wells (four/plate). Higher corrected absorbance values indicate greater cell viability.

After viability assays, cells were fixed in ice-cold acetone/ methanol (1:1) for 10 minutes. Cells were permeabilized in $0.25 \%$ Triton X-100 (Sigma, St. Louis, MO) for 10 minutes at $25^{\circ} \mathrm{C}$ and blocked in $5 \%$ goat serum in $1 \times \mathrm{PBS}$ for 1 hour. Cells were then incubated for 1 hour at $37^{\circ} \mathrm{C}$ with $1: 25$ mouse antichicken myosin heavy chain primary antibody (MF-20; Developmental Studies Hybridoma Bank, University of Iowa, Iowa City) in blocking solution. Cells were then rinsed and incubated at $37^{\circ} \mathrm{C}$ for 1 hour with 1:500 goat anti-mouse IgG2b Alexa-Fluor 555-conjugated secondary antibody and NucBlue fixed cell nuclear stain (R37605; Thermo Fisher). Cells were rinsed and imaged in PBS on an Evos FL Automicroscope with a $10 \times$ air objective, as described in Perfused Vessel Labeling. Myosin heavy chain-positive area/10 $\times$ image and number of nuclei/10 $\times$ image were measured by autothresholding each image using the default thresholding algorithm in ImageJ version 1.5lf. Nuclear counts were obtained using the Analyze Particles command (circularity 0-1.0).

\section{Dystrophin Immunofluorescence and Myofiber Permeability}

Twenty-four hours before HLI surgery, mice were injected intraperitoneally with Evans Blue Dye [EBD; $1 \%$ body weight of a $1 \%$ dye solution in sterile $1 \times \mathrm{PBS} ; n=7 /$ strain for BALB/c and C57BL/6, and $n=4$ for $\mathrm{A} / \mathrm{J}$ and $129 \mathrm{~S}$ (Sigma Aldrich)]. ${ }^{37}$ Systemic distribution of Evans Blue Dye was easily confirmed by its presence in the skin, resulting in blue skin tone. One C57BL/6 mouse was excluded because of lack of apparent dye distribution. Mice were subjected to 6 
hours of acute hind limb ischemia, as described in Model of Acute Hind Limb Ischemia. The tibialis anterior muscles were isolated from the ischemic limbs, embedded in OCT medium, and frozen in liquid nitrogen-cooled isopentane for cryosectioning. Sections (10 $\mu \mathrm{m}$ thick) were cut using a CM3050S cryostat (Leica) and collected on charged glass slides. Sections were then fixed in 1:1 acetone/methanol for 10 minutes at $-20^{\circ} \mathrm{C}$, rehydrated in $1 \times \mathrm{PBS}$, and blocked in $5 \%$ goat serum $+1 \times$ PBS for 1 hour at room temperature. Sections were then incubated with rabbit anti-human dystrophin primary antibody at $4^{\circ} \mathrm{C}$ overnight to counterstain for total vessels (1:100 dilution; Thermo Rb-9024; targeted to the protein $\mathrm{C}$-terminus). Sections were washed $3 \times$ for 10 minutes with cold $1 \times$ PBS and incubated for 1 hour with Alexa-Fluor 488-conjugated anti-rabbit IgG secondary antibody (1:250; Invitrogen). Sections were mounted using Vectashield hard mount medium without DAPI (Vector Labs). Images were taken at the anterolateral, central, and ventromedial positions within each muscle section on an Olympus FV1000 laser scanning confocal microscope with Fluoview FSW acquisition software version 4.2 (Olympus, Tokyo, Japan). The following parameters were used for laser scanning confocal microscope imaging: $20 \times$ air objective [numerical aperture $=0.5$, UPLFLN20X $(\mathrm{F})$; Olympus, Shinjuku, Tokyo, Japan], 4 microsecond/pixel scan rate, 1:1 aspect ratio, and sequential scan mode with line scanning Kalman filter $(\times 5)$. Alexa-Fluor 488 excitation was achieved using the 488-nm line of a multiline argon laser, and fluorescence emission was collected at $525 \mathrm{~nm}$. EBD excitation was achieved using a 559-nm laser diode, and fluorescence emission was collected at $680 \mathrm{~nm}$.

\section{Statistical Analysis}

Group means were compared using multiple $t$-tests. A distribution-free test ( $U$-test) was used for histomorphological clinical scoring because of the observed bimodal distribution of injury in C57BL/6 mice in the pilot studies. $P<0.05$ was considered statistically significant. All statistical analysis and visualization was performed using GraphPad Prism version 7.0b (GraphPad Software, La Jolla, CA). All image analysis was performed using ImageJ version 1.51f. ${ }^{34}$ Clinical scoring of H\&E images was performed by three independent blinded investigators (T.E.R., A.J.A., E.J.G.), and the median score was used in the final calculation. All image processing was applied across the whole image being processed. Image processing was applied uniformly across all images of comparable groups. Representative images were contrast enhanced with a $0.3 \%$ pixel saturation threshold. Unsharp mask filtering was applied to representative images to enhance feature separation after resizing (mask weight $=0.6$; pixel radius $=1$ ). Images used for quantification were not altered in any way that would affect the image histograms. Representative images in figure panels were zoomed digitally to enhance features for the reader. Select image panels showing representative subgroups at the original acquisition magnification are available in the online supplement.

\section{Results}

\section{Perfusion Reduction Is Similar in C57 and B/c Mice after Induction of Acute HLI}

The confounding influence of varying method in measurements of ischemic limb blood flow contributes to inconsistencies among comparative measurements between $\mathrm{C} 57$ and B/c mice across the literature published to date. For the sake of clarity, we first set out to report a complete set of baseline blood flow data using our described method. No differences in LDPI perfusion were detected in the medial thigh of either strain at baseline (Figure 1, A, C, and D). A strain effect $(P<0.001)$ (Table 1) was detected in the plantar paw when measurements were taken in the prone position, and it was consistent in both limbs (Figure 1, B, E, and F). To assess potential strain-dependent hemodynamic differences at baseline, tissue oxygen saturation during acute occlusion and reactive hyperoxia during reperfusion were assessed (Figure 1G). Temporary occlusion of the femoral artery resulted in complete depletion of tissue oxygen in the medial thigh (vastus medialis), indicating that occlusion in this anatomical position results in the same degree of acute ischemic burden in both strains. Mean peak tissue oxygen saturation during reperfusion was significantly lower in $\mathrm{B} / \mathrm{c}$ mice $(\mathrm{C} 57$ versus $\mathrm{B} / \mathrm{c}, 39.4 \% \pm 1.7 \%$ versus $31.0 \% \pm 2.1 \%$; $P<0.01$ ) (Figure $1 \mathrm{H}$ ). There was no effect of strain on time to nadir. The time to peak reperfusion in $\mathrm{B} / \mathrm{c}$ mice was more variable and trended longer than in $\mathrm{C} 57$ mice $(\mathrm{C} 57$ versus $\mathrm{B} / \mathrm{c}$, $39 \pm 2$ versus $54 \pm 6$ seconds; $P=0.07$ ) (Figure 1I).

Acute HLI was induced by double ligation and transection of the femoral artery distal to the deep and iliacofemoral artery branches and proximal to the lateral circumflex femoral artery branch (Supplemental Figure S1). Neither the lateral circumflex nor the femoral veins were compromised during separation in any of the animals used in this study. Perfusion in the medial thigh and plantar paw was significantly decreased compared with the control limb in both parental strains (Table 1, Figure 2, and Figure 3, A-F). A significant difference between strains in the plantar paw was detected immediately after surgery (Figure 2) and at 6-hours after surgery (Figure 3). A difference in the medial thigh was only detected immediately after surgery (Table 1 and Figure 2). Effect sizes of only approximately $5 \%$ to $10 \%$ of residual perfusion normalized to the contralateral control limbs were observed between the strains.

To further investigate the perfusion differences observed between the strains, additional measurements of tissue oxygen saturation and perfusion were used. Laser Doppler point flowmetry was used to measure perfusion independent of noise produced by skin pigment. Flux in the lateral gastrocnemius, after removal of the skin and fascia, was reduced in the ischemic limbs of both strains (C57 versus B/c, 
A

\section{Supine Position}

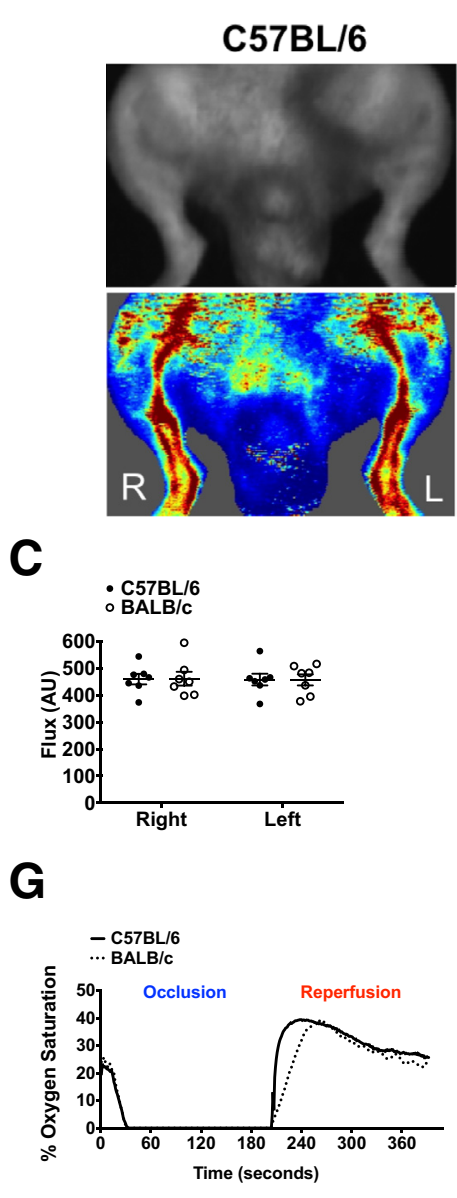

B

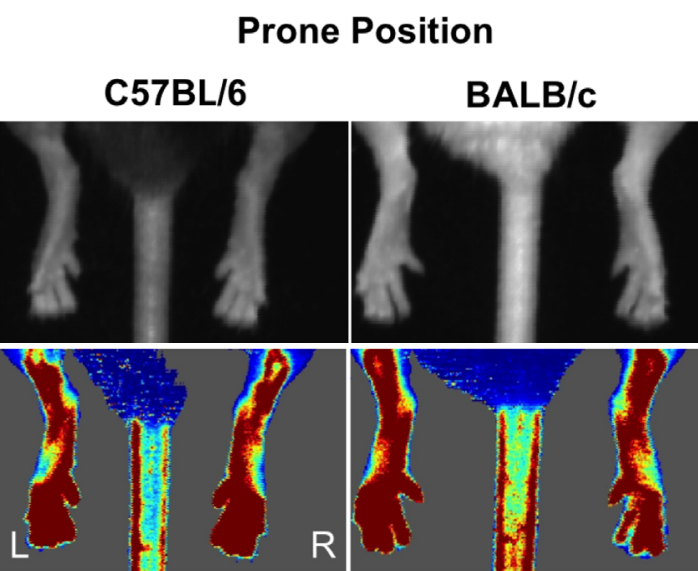

E
$\mathbf{F}$

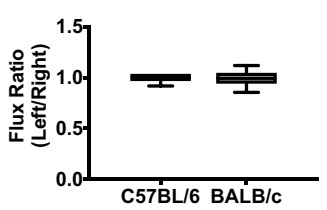

H

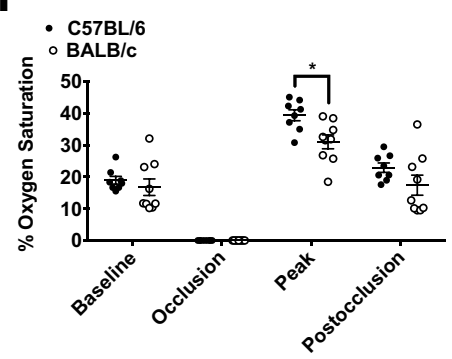

BALB/c

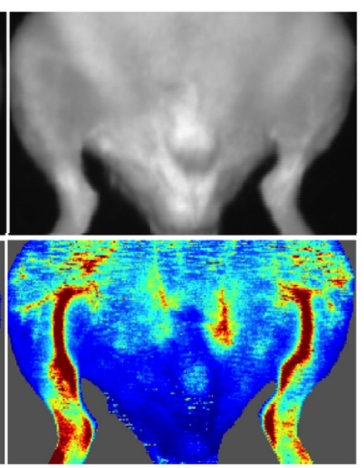

D

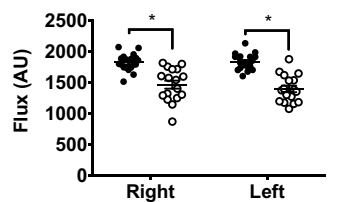

I

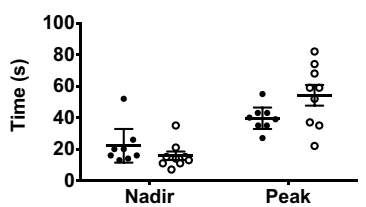

Figure 1 Perfusion status and hemodynamics are similar at baseline in C57 and B/c parental strains of mice. A: Representative camera and laser Doppler perfusion images (LDPIs) of the left $(L)$ and right (R) limbs in the supine position at baseline. B: Representative LDPIs of the $L$ and $R$ plantar paws in the prone position at baseline. $\mathbf{C}$ and $\mathbf{D}$ : Quantification of flux measurements in the supine position represented as arbitrary perfusion units (AUs) and as a ratio of the left over the right limbs. $\mathbf{E}$ and $\mathbf{F}$ : Quantification of flux measurements in the prone position. G: Representative traces showing postocclusive reactive hyperoxia (PORH), measured by white light reflectance spectroscopy, in the left vastus medialis muscle after 3-minute occlusion and 3-minute reperfusion of the femoral artery. H: Percentage oxygen saturation values measured during PORH protocol. I: Time to nadir/peak after occlusion and reperfusion. Bars in box-and-whisker plots indicate median, interquartile range, and maximum/minimum values ( $\mathbf{D}$ and $\mathbf{F})$. Data are expressed as means \pm SEM $(\mathbf{C}, \mathbf{E}, \mathbf{H}$, and $\mathbf{I}) . n=7 \mathrm{BALB} / \mathrm{C}(\mathbf{C}$ and $\mathbf{D}) ; n=8 \mathrm{C} 57 \mathrm{BL} / 6(\mathbf{C}$ and $\mathbf{D}) ; n=20$ per group $(\mathbf{E}$ and $\mathbf{F}) ; n=1$ per group $(\mathbf{G}) ; n=8$ per group $(\mathbf{H}$ and $\mathbf{I}) .{ }^{*} P<0.05$.

$136.0 \pm 11.4$ versus $75.0 \pm 13.4$ arbitrary units) (Figure 3, G and $\mathrm{H}$ ). Similar to LDPI measurements described in the previous paragraph, the effect size compared with the contralateral control limb was relatively small (C57 versus $\mathrm{B} / \mathrm{c}$, $27 \% \pm 0.03 \%$ versus $15 \% \pm 0.02 \%$ ), suggesting only a $12 \%$ difference in residual flux between strains. White light reflectance spectroscopy was used to determine tissue oxygen saturation directly over the muscles (after removal of the skin and fascia) of the proximal and distal limb. A proximal-todistal pattern of decreased tissue oxygen saturation in the ischemic limbs of both strains was observed, with no statistically significant strain differences (Figure 3I). For visualization of perfused microvessels, animals were given a systemic injection of fluorophore-conjugated lectin (Dylight594-Griffonia simplificolia isolectin $\mathrm{B}_{4}$ ) in the retro-orbital sinus immediately after induction of HLI. The isolectin $\mathrm{B}_{4}$ subunit chosen for this study binds galactosecontaining moieties in the endothelial glycocalyx, thereby labeling perfused blood vessels. A proportional shift in perfused vessel-positive area in the ischemic limb relative to the contralateral control limb was observed in both strains. A statistically significant strain effect was detected in the gastrocnemius muscles (C57 versus B/c, $1521 \pm 92$ versus $885 \pm 142 \mu \mathrm{m}^{2}$ ) (Figure 4, A and D). Commensurate with both the LDPI and laser Doppler flowmetry data, the effect size compared with the contralateral control limb was only approximately $11 \%(\mathrm{C} 57$ versus $\mathrm{B} / \mathrm{c}, 26.9 \% \pm 0.03 \%$ versus $15.5 \% \pm 0.03 \%$ ) (Figure 4, A and E). In addition, endothelial cell junction marker CD31 (platelet endothelial cell adhesion molecule 1) was counterstained to indicate total vessel 
Table 1 Absolute LDPI Perfusion Values and Ratios Normalized for Baseline Differences in the Contralateral Control Limbs in the Paw and Medial Thighs of $\mathrm{C} 57 \mathrm{BL} / 6$ and BALB/C Mice before and after Hind Limb Ischemia

\begin{tabular}{lccccc}
\hline & \multicolumn{2}{l}{ C57BL/6 mice } & \multicolumn{3}{l}{ BALB/c mice } \\
\cline { 2 - 3 } \cline { 5 - 6 } Time point & Ctrl. (R) & Isch. (L) & & Ctrl. (R) & Isch. (L) \\
\hline Pre (thigh) & $459 \pm 19$ & $458 \pm 21$ & & $461 \pm 25$ & $456 \pm 20$ \\
Post & $360 \pm 14$ & $160 \pm 9^{*}$ & & $342 \pm 12$ & $114 \pm 9$ \\
At 6 hours & $474 \pm 24$ & $214 \pm 16$ & $424 \pm 31$ & $182 \pm 15$ \\
Pre (paw) & $1706 \pm 44^{*}$ & $1689 \pm 45^{*}$ & $1294 \pm 53$ & $1312 \pm 61$ \\
Post & $1582 \pm 32^{*}$ & $170 \pm 19^{*}$ & $1210 \pm 77$ & $49 \pm 8$ \\
At 6 hours & $1766 \pm 46^{*}$ & $177 \pm 17^{*}$ & $1281 \pm 74$ & $81 \pm 8$ \\
\hline & \multicolumn{2}{c}{ Isch. (L)/Ctrl. (R) } & \multicolumn{2}{c}{ Isch. (L)/Ctrl. (R) } \\
\hline Pre (thigh) & \multicolumn{2}{c}{$1 \pm 0.01$} & & $1 \pm 0.03$ \\
Post & $0.45 \pm 0.01$ & & $0.34 \pm 0.03$ \\
At 6 hours & $0.45 \pm 0.02$ & & $0.43 \pm 0.02$ \\
Pre (paw) & $0.99 \pm 0.01$ & & $1 \pm 0.04$ \\
Post & $0.10 \pm 0.01$ & & $0.04 \pm 0.00$ \\
At 6 hours & $0.10 \pm 0.01$ & & $0.06 \pm 0.00$ \\
\hline
\end{tabular}

Data are expressed as means \pm SEM. Arbitrary units are given.

${ }^{*} P<0.05$ versus $\mathrm{BALB} / \mathrm{c}$.

At 6 hours, LDPI flux ratio after 6 hours of hind limb ischemia; Ctrl. (R), control right; Isch. (L), ischemic left; LDPI, laser Doppler perfusion imaging; Pre, LDPI flux ratio before hind limb ischemia; Post, LDPI flux ratio immediately after hind limb ischemia.

content (Figure 4, A-C). No significant differences were observed. Overall, these detailed measures collectively suggest that the reduction in blood flow and muscle perfusion to the ischemic limb after HLI is only slightly greater in $\mathrm{B} / \mathrm{c}$ mice compared with C57 mice. This decrease, however, is not sufficient to result in measureable differences in tissue oxygen saturation (Figure 3I).

\section{B/c Mice Experience Dramatic Early Ischemic Muscle Damage Compared with C57 Mice}

Histologic analyses of the tibialis anterior and gastrocnemius muscles were performed in both strains after 6 hours of acute hind limb ischemia. The observed ischemic injury was characterized by the following: small rounded basophilic fibers, large rounded acidophilic fibers, apparent necrotic (disintegrated) fibers, expanded interstitial space compared with a typical healthy control, and aggregates of generalized cells in the interstitium (Supplemental Figure S2). Dramatic signs of muscle damage were observed in all of the $\mathrm{B} / \mathrm{c}$ mice examined (Figure 5A and Supplemental Figure S3). Reduced or complete lack of apparent damage was observed in C57 mice. This pattern in C57 mice appeared to follow a bimodal distribution in independent study cohorts tested at different times under the same carefully controlled conditions (Figure 5, A-C, and Supplemental Figure S3). The degree of tissue damage did not assort by perfusion level in either strain (Figure 5, D and E), suggesting a dissociation of skeletal muscle myofiber morphologic abnormalities from the degree of perfusion reduction. Interestingly, force production ex vivo was not reached at submaximal or maximal stimulation frequencies in isolated extensor digitorum longus muscles of either strain after 6 hours of HLI (Figure 5F). During isolated muscle contractile experiments, incubation for 10 minutes with either exogenous $10 \mathrm{mmol} / \mathrm{L}$
A

\section{Supine Position}
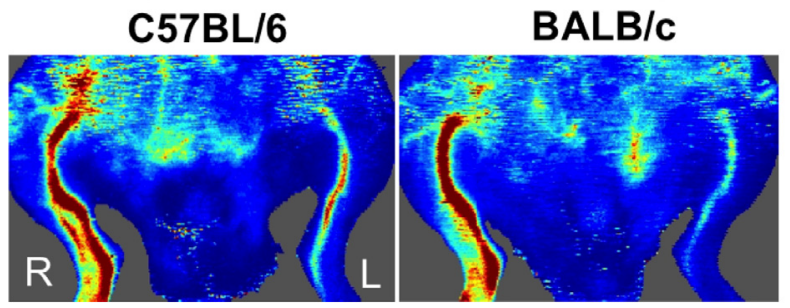

C

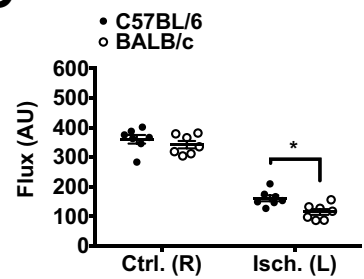

D

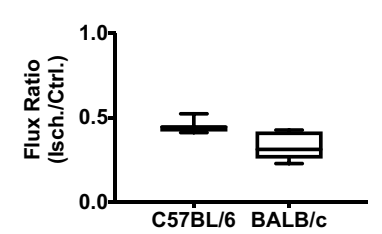

B
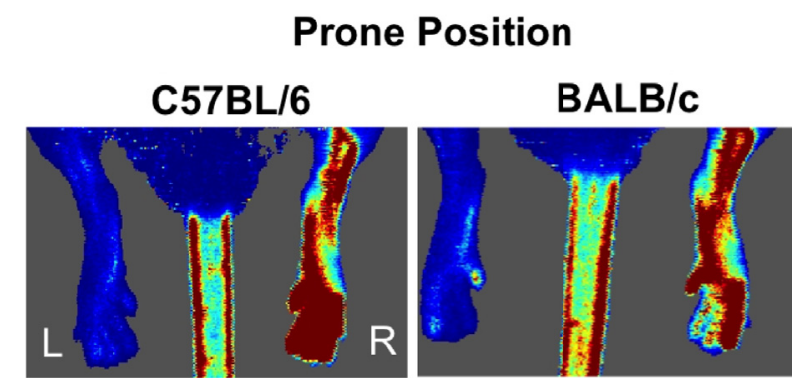

E

$\mathbf{F}$
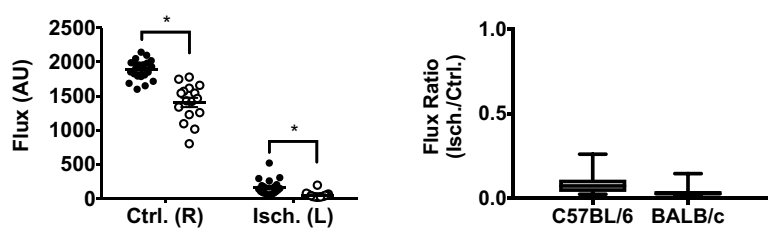

Figure 2 Perfusion status is similar in $\mathrm{C} 57$ and B/C mice immediately after femoral artery ligation. A: Representative laser Doppler perfusion images (LDPIs) of the ischemic left [Isch. (L)] and control right [Ctrl. (R)] limbs in the supine position immediately after hind limb ischemia surgery. B: Representative LDPIs of the Isch. (L) and Ctrl. (R) plantar paws in the prone position. $\mathbf{C}$ and $\mathbf{D}$ : Quantification of flux measurements in the supine position represented as arbitrary perfusion units (AUs) and as a ratio of the left over the right limbs. $\mathbf{E}$ and $\mathbf{F}$ : Quantification of flux measurements in the prone position represented as $\mathrm{AUs}$ and as a ratio of the left over the right limbs. Bars indicate median, interquartile range, and maximum/minimum values (D and $\mathbf{F})$. Data are expressed as means $\pm \mathrm{SEM}(\mathbf{C}$ and $\mathbf{E}) . n=7 \mathrm{BALB} / \mathrm{C}(\mathbf{C}$ and $\mathbf{D}) ; n=8 \mathrm{C} 57 \mathrm{BL} / 6(\mathbf{C}$ and $\mathbf{D}) ; n=20$ per group $(\mathbf{E}$ and $\mathbf{F}) .{ }^{*} P<0.05$. 
A

\section{Supine Position}
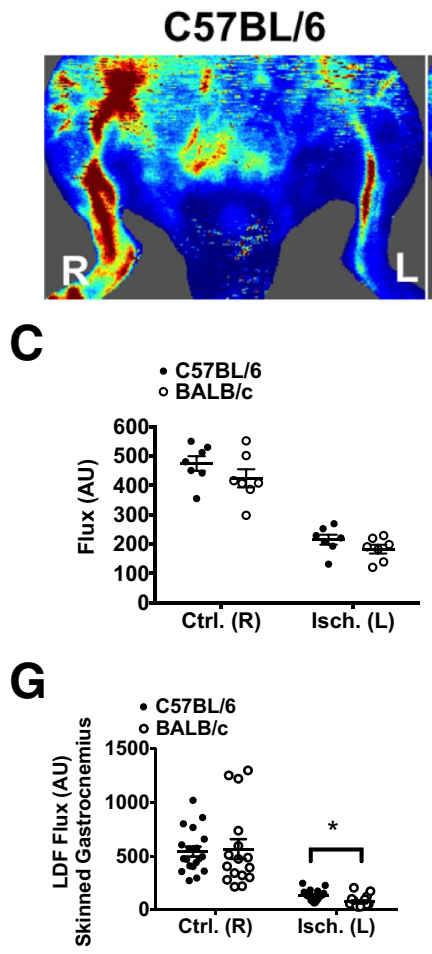

$\mathrm{H}$
B

\section{Prone Position}
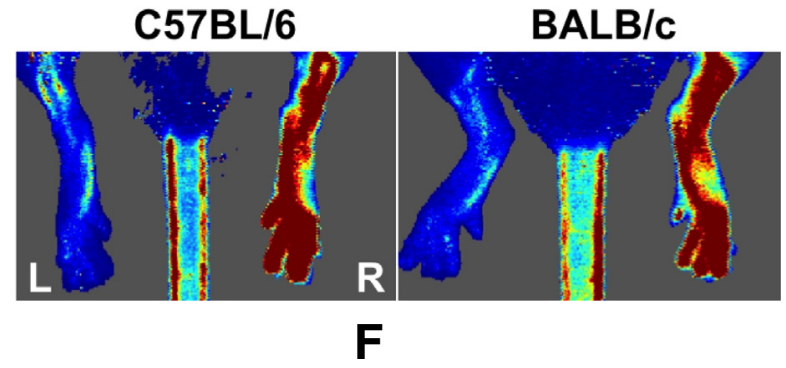

D E
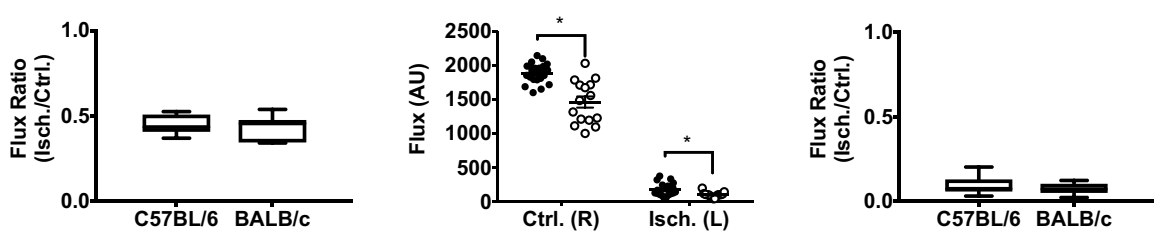

I

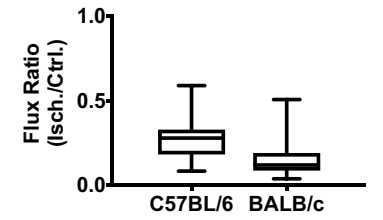

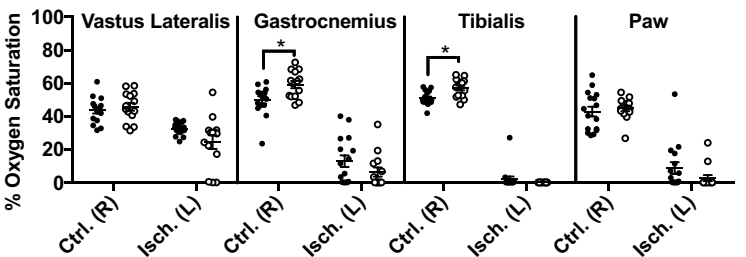

Figure 3 Residual blood perfusion and tissue oxygenation are similar in the ischemic limbs of C57 and B/c mice after 6 hours of acute hind limb ischemia. A: Representative laser Doppler perfusion images (LDPIs) of the ischemic left [Isch. (L)] and control right [Ctrl. (R)] limbs in the supine position after 6 hours of acute hind limb ischemia. B: Representative LDPIs of the Isch. (L) and Ctrl. (R) limbs in the prone position after 6 hours of acute hind limb ischemia. C and D: Quantification of flux measurements in the supine position represented as arbitrary perfusion units (AU) and as ratio of the Isch. (L)/Ctrl. (R) limbs. $\mathbf{E}$ and $\mathbf{F}$ : Quantification of flux measurements in the prone position represented as AUs and as a ratio of the Isch. (L)/Ctrl. (R) limbs. G and $\mathbf{H}$ : Laser Doppler flowmetry (LDF) measurements made directly over the lateral head of the gastrocnemius muscles in the absence of interference from skin pigmentation. I: Percentage oxygen saturation values measured directly over the vastus lateralis, lateral head of the gastrocnemius, tibialis anterior, and plantar paw in the Ctrl. (R) and Isch. (L) limbs of both strains. Bars indicate median, interquartile range, and maximum/minimum values (D, F, and $\mathbf{H})$. Data are expressed as means \pm SEM (C, E, G, and I). $n=7 \mathrm{BALB} / \mathrm{C}(\mathbf{C}$ and $\mathbf{D}) ; n=8 \mathrm{C} 57 \mathrm{BL} / 6(\mathbf{C}$ and $\mathbf{D}) ; n=14$ per group $(\mathbf{E}$ and $\mathbf{F}) ; n=18$ per group $(\mathbf{G}$ and $\mathbf{H}) ; n=14$ per group $(\mathbf{I}) .{ }^{*} P<0.05$.

glucose or $10 \mathrm{mmol} / \mathrm{L}$ glucose + insulin did not elicit contraction (data not shown). In addition, force production in isolated soleus muscles was not achieved under the same conditions (data not shown). Taken together, these observations suggest that muscle energetic impairment occurred throughout the hind limb muscle anatomy and was most likely irreversible.

Surgical or anatomic variation may lead to the observed bimodal distribution of muscle damage in C57 mice. To address this, laser Doppler perfusion data were stratified post hoc into two groups: animals demonstrating ischemic muscle damage confirmed by $\mathrm{H} \& \mathrm{E}$ staining and animals demonstrating no ischemic muscle damage. This was performed in two independent study cohorts, with laser Doppler measurements taken in two anatomical regions (plantar paw or medial thigh), and with ischemic damage confirmed in two different muscles (tibialis anterior or gastrocnemius). The presence or absence of signs of ischemic muscle damage was not associated with differences in the degree of residual perfusion
(Supplemental Figure S4, A and B). This post hoc stratification method was used to compare perfused vessel (Griffonia simplicolia isolectin- $\mathrm{B}_{4}-$ lectin) labeling in the gastrocnemius muscles. There was no apparent association between perfused vessel area and ischemic muscle damage in the gastrocnemius (Supplemental Figure S4C). Furthermore, H\&E-stained sections of tibialis anterior muscles were assessed after 24 and 72 hours of acute hind limb ischemia, and it was discovered that the bimodal distribution of tissue damage was similar to that observed at 6 hours, indicating that the decreased initial degree of damage in C57 mice is consistent at later time points among independent cohorts of animals (Supplemental Figure S4, D-F).

To assess myofiber permeability quantitatively in vivo, systemic injection of EBD was used. Fibers with an intact sarcolemma are impermeable to the albumin bound by the EBD. B/c mice had an increased number of EBD-positive fibers in the tibialis anterior muscles after ischemia, although not statistically significant $(P=0.11)$ (Figure 5, G and $\mathrm{H})$. The number of EBD-positive fibers was bimodally 
A

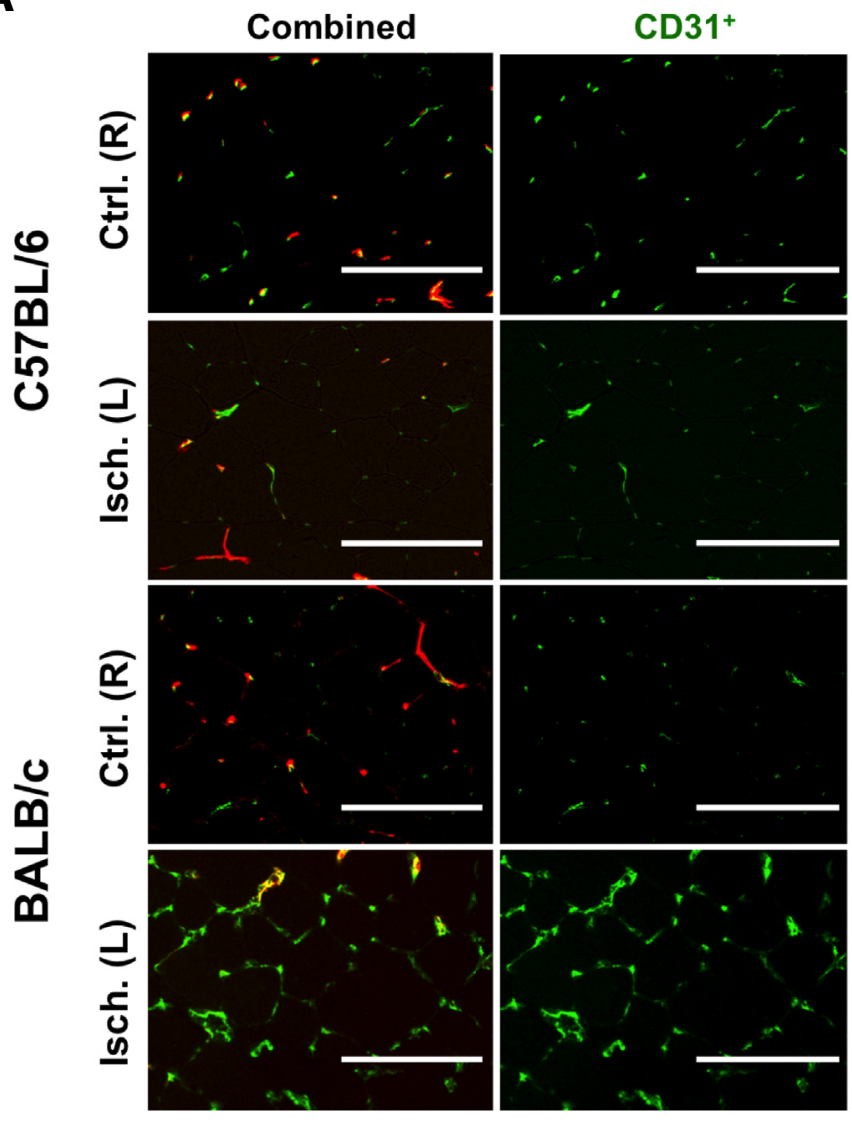

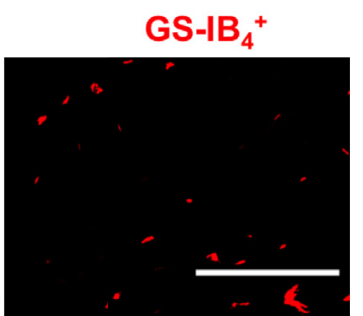

B

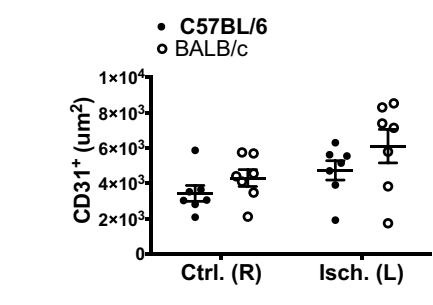

C
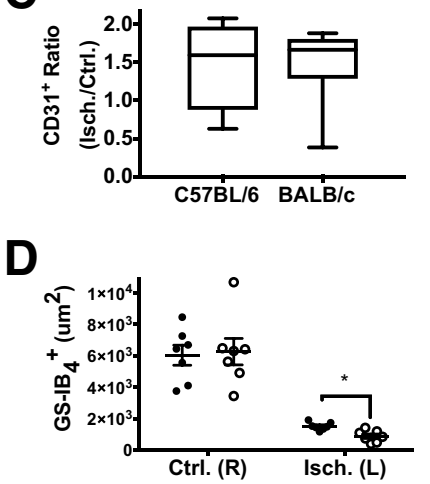

$\mathbf{E}$

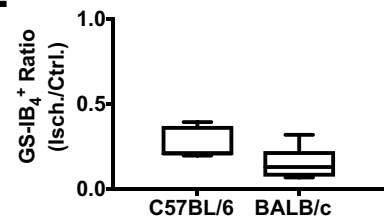

Figure 4 Total and perfused vessels are similar in the ischemic muscle of $\mathrm{C} 57$ and B/c mice after 6 hours of acute hind limb ischemia. A: Representative immunofluorescence images of $\mathrm{CD}_{1}{ }^{+}$(platelet endothelial cell adhesion molecule 1), indicating total vessels; and systemically injected Dylight594-conjugated Griffonia simplicolia isolectin- $\mathrm{B}_{4}\left(\mathrm{GS}_{\mathrm{S}} \mathrm{IB}_{4}\right)$ lectin, indicating perfused vessels in transverse sections of gastrocnemius muscle from both strains after 6 hours of acute hind limb ischemia. Representative images are $2 \times$ digital zoom from images. B and C: Mean total vessel CD31 ${ }^{+}$area per image in the control right [Ctrl. (R)] and ischemic left [Isch. (L)] limbs represented by absolute values and the ratio of the Isch./Ctrl. limbs. D and E: Mean total vessel (lectin-Dylight594 $4^{+}$) area per image in the control right and ischemic left limbs represented by absolute values and the ratio of the Isch./Ctrl. limbs. Bars indicate median, interquartile range, and maximum/minimum values (C and $\mathbf{E})$. Data are expressed as means \pm SEM (B and $\mathbf{D})$. $n=7$ animals per group. ${ }^{*} P<0.05$. Scale bars $=50 \mu \mathrm{m}(\mathbf{B}$ and $\mathbf{D})$. Original magnification: $\times 20(\mathbf{A}-\mathbf{E})$.

distributed in C57 mice, with some mice displaying a complete lack of muscle damage, similar to other independent cohorts used in this study (Figure 5H and Supplemental Figures S5, S6, and S7). There was also a statistically significant decrease in the number of dystrophin-positive myofibers in $\mathrm{B} / \mathrm{c}$ mice compared with $\mathrm{C} 57$ mice, indicating early loss of this key structural protein that appeared commensurate with the number of EBD-positive fibers (Figure 5H).

Muscle Myofiber Sensitivity to Ischemic Injury Differs between $\mathrm{C} 57$ and B/c Mice, Independent of Residual Flow Differences

To assess the muscle response to ischemic injury in the complete absence of residual perfusion in vivo, histomorphology was assessed at 3 and 6 hours postmortem in mice euthanized by cervical dislocation to model ischemia in the complete absence of residual flow. No statistically significant differences were detected in tibialis anterior clinical scores at any of the observed time points assessed; however, C57 mice had lower (nonsignificant) trending scores at 3 hours postmortem $(\mathrm{C} 57$ versus B/c, 4.5 versus 10; aggregate clinical score; $P=0.25$ ) (Figure $6, \mathrm{~A}$, $\mathrm{C}$, and $\mathrm{D}$ ). The clinical scoring system used was the same as described in B/c Mice Experience Dramatic Early Ischemic Muscle Damage Compared with C57 Mice (Supplemental Figure S2). A statistically significant difference in the number of dystrophin-positive myofibers was detected at 3 hours postmortem between the strains (C57 versus B/c, $123 \pm 84$ versus $8 \pm 1$; mean dystrophin-positive fibers/ $\times 10$ field; $P=0.01$ ) (Figure $6, \mathrm{~B}, \mathrm{E}$, and F). A DAPI nuclear counterstain was performed for contrast, and it indicated no difference in the number of nuclei present per field in either strain or at either time point (Figure 6F). All but one of the C57 mice experienced loss of dystrophin immunostaining similar to B/c mice by 6 hours postmortem (Figure 6, B and E, and Supplemental Figure S8). 
A

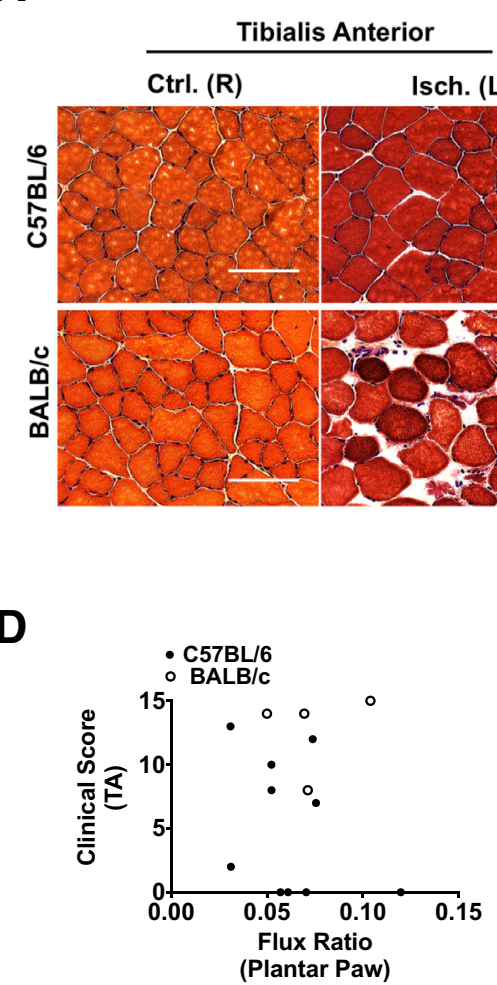

G
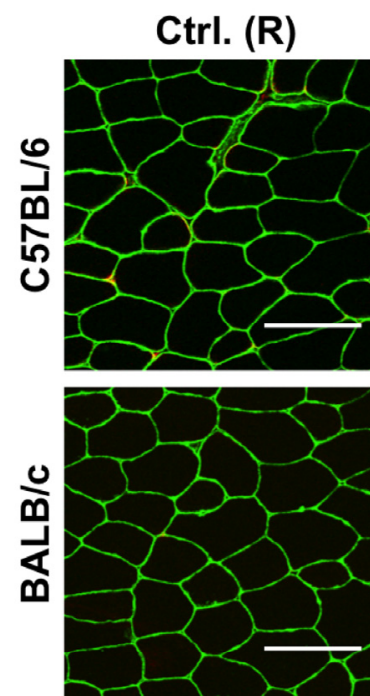

Dystrophin; Evans Blue Dye
B

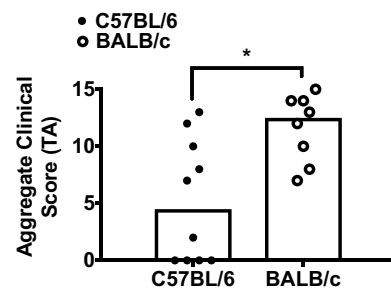

C

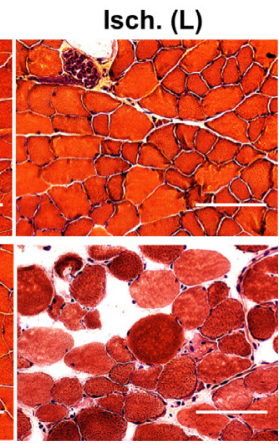

E

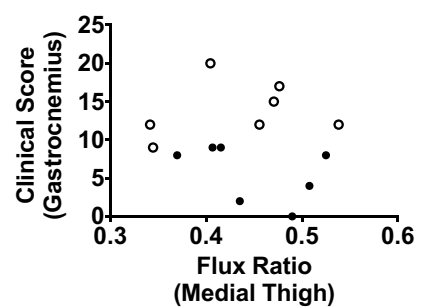

H

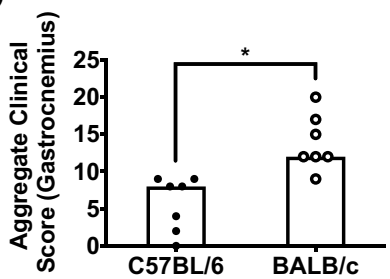

F

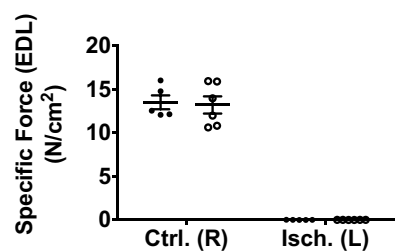

- C57BL/6

- BALB/c

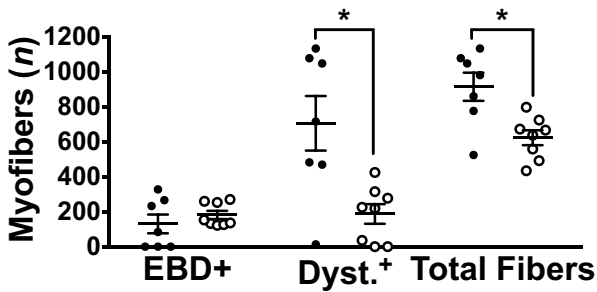

Figure 5 Skeletal muscle histomorphology, myofiber permeability, and dystrophin immunostaining differ significantly in C57 and B/c mice after 6 hours of acute hind limb ischemia, despite muscle functional impairment in both strains. A: Representative images of hematoxylin and eosin-stained sections from the control right [Ctrl. (R)] and ischemic left [Isch. (L)] tibialis anterior (TA) and gastrocnemius muscles. B: Aggregate clinical scores from three images for each animal assessed in the tibialis anterior muscles; maximal score of 15 indicates most severe ischemic damage. C: Aggregate clinical scores from five images for each animal assessed in the gastrocnemius muscles; maximal score of 25 indicates most severe ischemic damage. D: Scatter plot of clinical score in the TA versus laser Doppler perfusion images (LDPI) flux ratio in the plantar paw. E: Scatter plot of clinical score in the gastrocnemius versus LDPI flux ratio in the medial thigh. F: Peak specific force production after maximal stimulation $(120 \mathrm{~Hz})$ in isolated extensor digitorum longus (EDL) muscles represented in $\mathrm{N} / \mathrm{cm}^{2}$. G: Representative images of Evans Blue Dye (EBD)-positive myofibers and dystrophin immunostaining in transverse sections of Isch. (L) and (trl. (R) TA muscles from both strains after 6 hours of hind limb ischemia. H: Mean number of $\mathrm{EBD}^{+}$, dystrophin-positive (Dyst. ${ }^{+}$), or total fibers from three images for each animal assessed in the Isch. (L) TA muscles of both strains. Representative images are $2 \times$ digital zoom from images. Bars indicate the median (B and $\mathbf{C})$. Data are expressed as means $\pm \mathrm{SEM}(\mathbf{F}$ and $\mathbf{H}) . n=8 \mathrm{BALB} / \mathrm{c}(\mathbf{B}) ; n=10 \mathrm{C} 57 \mathrm{BL} / 6(\mathbf{B}) ; n=7$ per group $(\mathbf{C}) ; n=4 \mathrm{BALB} / \mathrm{c}(\mathbf{D}) ; n=10 \mathrm{C57BL} / 6(\mathbf{D}) ; n=7$ per group $(\mathbf{E}) ; n=6$ per group $(\mathbf{F}) ; n=8 \mathrm{BALB} / \mathrm{C}(\mathbf{H}), n=7 \mathrm{C} 5 \mathrm{BL} / 6(\mathbf{H}) .{ }^{*} P<0.05$. Scale bars $=50 \mu \mathrm{m}(\mathbf{A}$ and $\mathbf{G})$. Original magnification: $\times 20(\mathbf{A}$ and $\mathbf{G})$. 
A

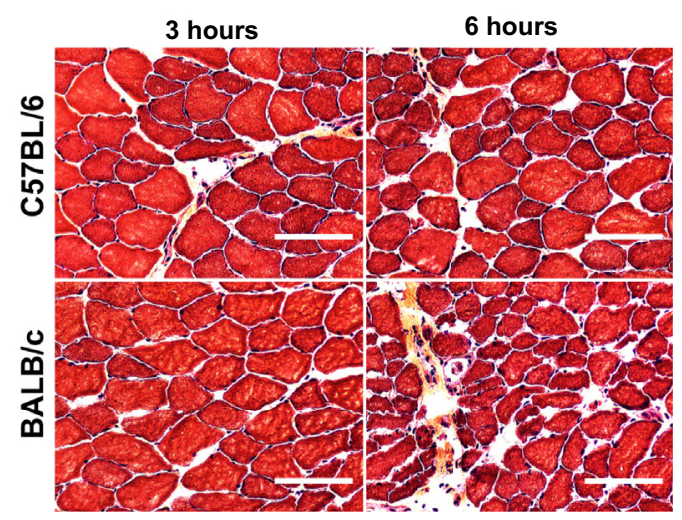

C
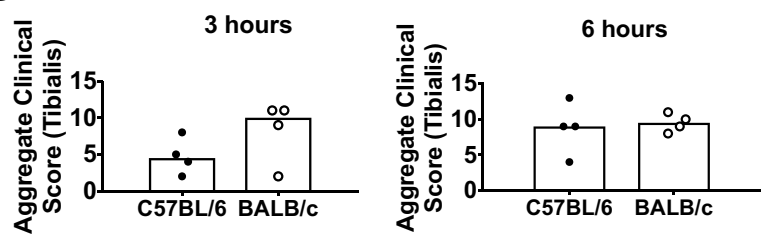

G

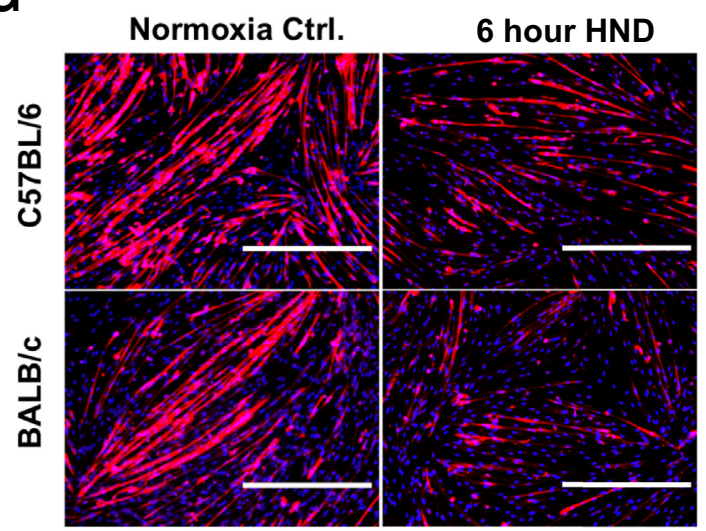

DAPI; Myosin Heavy Chain
B

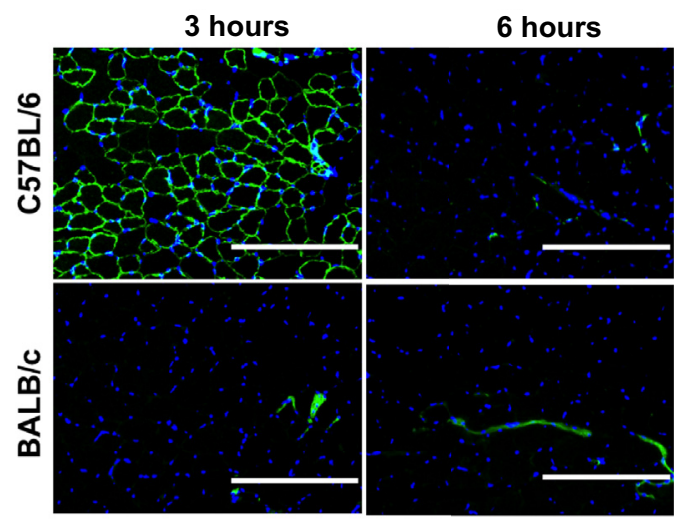

E

Dystrophin; DAPI

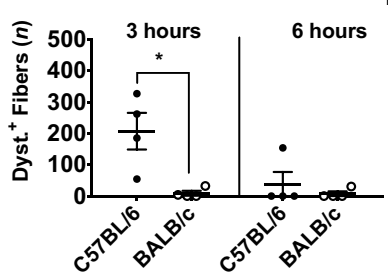

$F$

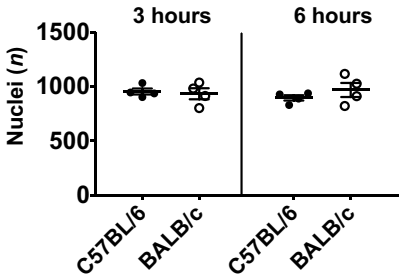

H

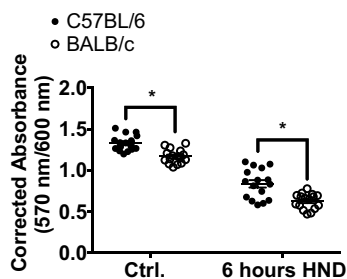

I

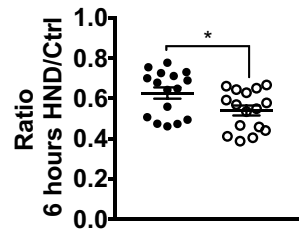

J

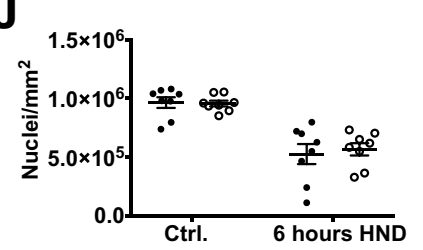

K

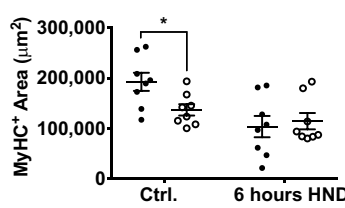

Figure 6 Skeletal muscle response to ischemia differs between $\mathrm{C} 57$ and B/c mice in the complete absence of residual flow. A: Representative images $(2 \times$ digital zoom) of hematoxylin and eosin-stained sections of tibialis anterior muscle from C57 and B/c mice at 3 and 6 hours after euthanasia by cervical dislocation (postmortem). B: Representative images (2x digital zoom) of dystrophin immunostaining in transverse sections of tibialis anterior muscles 3 and 6 hours postmortem. C and D: Aggregate clinical scores from three images for each animal assessed in the tibialis anterior muscles; maximal score of 15 indicates most severe ischemic damage. Bars in dot plots indicate the median. $\mathbf{E}$ and F: Mean number of dystrophin positive (Dyst. ${ }^{+}$) fibers and DAPI-stained nuclei 3 and 6 hours postmortem from two images for each animal assessed in the tibialis anterior of both strains. G: Representative images of myosin heavy chain (MyHC)-immunostained primary myotubes after exposure to 6 hours of hypoxia and nutrient deprivation (HND) or normoxia without nutrient deprivation. H and I: Cell viability indicated by corrected resorufin dye absorbance at $570 \mathrm{~nm}$ in primary myotubes represented as mean corrected absorbance and as a ratio of HND/normoxia controls (Ctrl). $\mathbf{J}$ and $\mathbf{K}$ : Number of DAPI-stained nuclei and MyHC immunostain-positive area were measured to indicate the relative amount of cells present after each treatment. Bars indicate means ( $\mathbf{C}$ and $\mathbf{D})$. Data are expressed as means $\pm \mathrm{SEM}(\mathbf{E}, \mathbf{F}$, and $\mathbf{H}-\mathbf{K}) . n=4$ animals per group $(\mathbf{A}-\mathbf{F}) ; n=16$ per group $(\mathbf{H}$ and $\mathbf{I}) ; n=8$ per group $(\mathbf{J}$ and $\mathbf{K}) .{ }^{*} P<0.05$. Scale bars: $50 \mu \mathrm{m}(\mathbf{A}) ; 200 \mu \mathrm{m}(\mathbf{B}) ; 400 \mu \mathrm{m}(\mathbf{G})$. Original magnification: $\times 10(\mathbf{B}, \mathbf{E}, \mathbf{F}-\mathbf{K}) ; \times 20(\mathbf{A}, \mathbf{C}, \mathbf{D})$.

To assess the muscle response to ischemic injury in the absence of residual perfusion differences in vitro, cell viability was assessed after 6 hours of hypoxia and nutrient deprivation using primary myotubes differentiated from muscle progenitor cells isolated from each strain. Decreased corrected resorufin absorbance was observed in both strains compared with normoxic controls (Figure 6, G and H). A small, but statistically significant, difference in absolute corrected resorufin absorbance, as well as absorbance normalized to the normoxia control, in $\mathrm{B} / \mathrm{c}$ myocytes compared with $\mathrm{C} 57$, indicating reduced $\mathrm{B} / \mathrm{c}$ myocyte viability after HND, was also observed (Figure 6, H and I). To account for potential loss of adherent cells during HND and subsequent wash steps, counts of DAPI-stained nuclei present in 
A

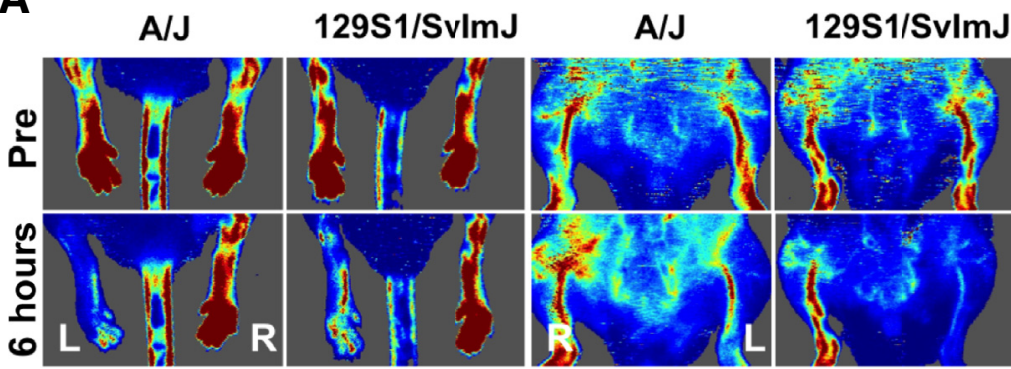

C

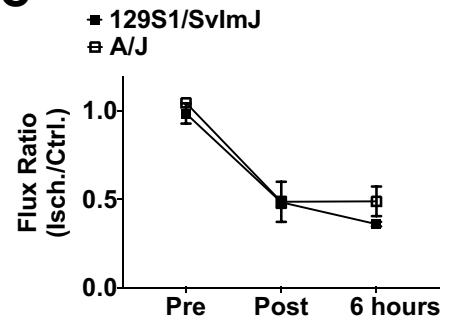

$\mathbf{F}$
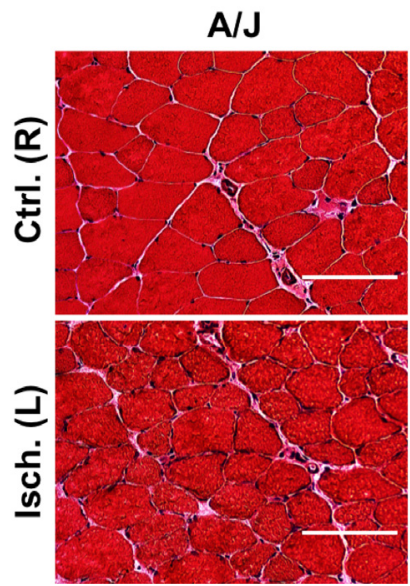

H

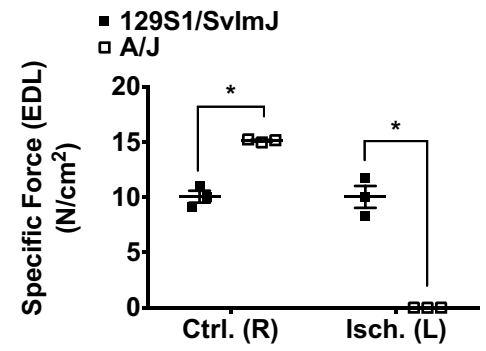

B

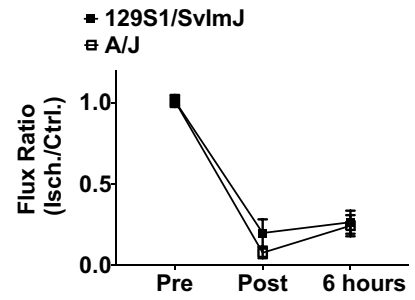

E

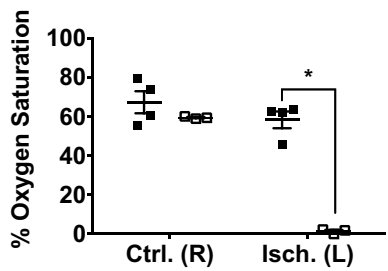

G

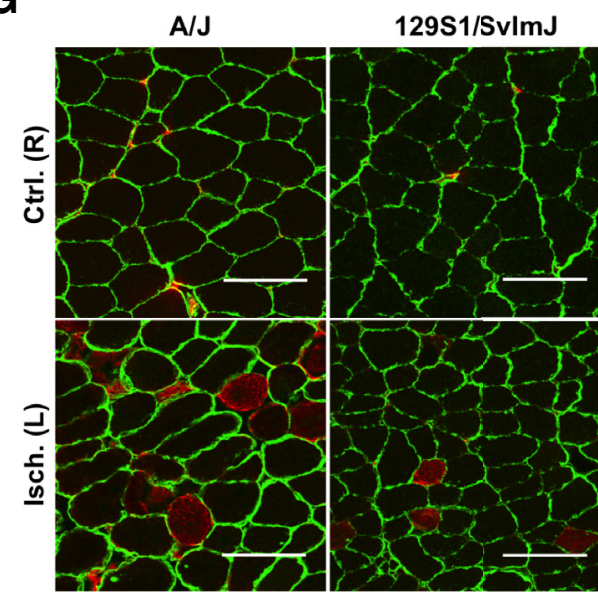

Dystrophin; Evans Blue Dye

I

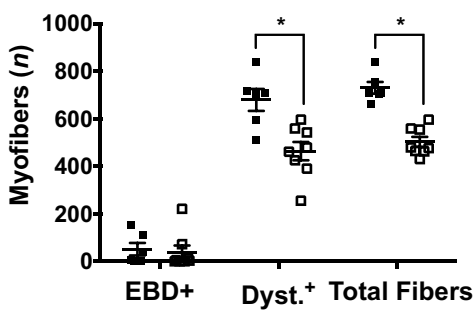

Figure 7 Dramatic ischemic muscle injury is not observed in additional inbred mouse strains tested. A: Representative laser Doppler perfusion images (LDPIs) of the ischemic left [Isch. (L)] and control right [Ctrl. (R)] limbs in the prone and supine positions at baseline and after 6 hours of hind limb ischemia (HLI). B: LDPI flux ratio before HLI (Pre), immediately after HLI (Post), and after 6 hours of HLI measured in the plantar paw. C: LDPI flux ratio Pre, Post, and after 6 hours of HLI measured in the medial thigh. D: Laser Doppler flowmetry (LDF) measurements made directly over the lateral head of the gastrocnemius muscles in the absence of interference from skin pigmentation after 6 hours of HLI in the Ctrl. (R) and Isch. (L) limbs. E: Percentage oxygen saturation values measured directly over the lateral head of the gastrocnemius in the Ctrl. (R) and Isch. (L) limbs. F: Representative images of hematoxylin and eosin-stained sections from the Ctrl. (R) and Isch. (L) gastrocnemius muscles. G: Representative images of Evans Blue Dye (EBD)-positive myofibers and dystrophin immunostaining in transverse sections of Isch. $(\mathrm{L})$ and $\mathrm{Ctrl}$. (R) gastrocnemius muscles from both strains after 6 hours of HLI. H: Peak specific force production after maximal stimulation $(120 \mathrm{~Hz})$ in isolated extensor digitorum longus $(\mathrm{EDL})$ muscles represented in units of N/ $\mathrm{cm}^{2}$. I: Mean number of EBD ${ }^{+}$, dystrophinpositive $\left(\right.$ Dyst. $^{+}$), or total fibers from two images for each animal assessed in the Isch. (L) gastrocnemius muscles of both strains. Data are expressed as means \pm SEM (B-E, $\mathbf{H}$, and $\mathbf{I})$. Representative images are $2 \times$ digital zoom from images collected at $\times 20(\mathbf{F}$ and $\mathbf{G})$. $n=4$ per group $(\mathbf{B}-\mathbf{E}) ; n=3$ per group $(\mathbf{H}) ; n=8 \mathrm{BALB} / \mathrm{c}(\mathbf{I}) ; n=6 \mathrm{C} 57 \mathrm{BL} / 6(\mathbf{I}) .{ }^{*} P<0.05$. Scale bars $=50 \mu \mathrm{m}(\mathbf{F}$ and $\mathbf{G})$. Original magnification: $\times 20(\mathbf{F}$ and $\mathbf{G}) ; \times 10(\mathbf{I})$. AU, arbitrary unit. 
each $10 \times$ image, as well as myosin heavy chain-positive area per image, were performed to indicate the relative amount of differentiated myotubes present (Figure 6, J and $\mathrm{K})$. No differences were observed in nuclear count or myosin heavy chain-positive area after 6 hours of HND.

\section{Dramatic Signs of Early Ischemic Muscle Injury Are Not Observed in Additional Inbred Strains Chosen for Their B/c-Like and C57-Like Preexisting Vascular Anatomy}

$\mathrm{A} / \mathrm{J}$ mice are considered to be a low collateral strain similar to $\mathrm{B} / \mathrm{c}$, and 129S mice are considered to be a high collateral strain similar to $\mathrm{C} 57$ mice. ${ }^{28}$ Adult male mice from each strain underwent 6 hours of HLI to determine whether the response observed in $\mathrm{B} / \mathrm{c}$ mice was primarily attributable to preexisting collateral vessel anatomy. Both strains experienced perfusion deficits after HLI (Figure 7, A-C). A/J mice experienced more complete ischemia than $129 \mathrm{~S}$, indicated by laser Doppler flowmetry and percentage oxygen saturation measured in the lateral gastrocnemius (Figure 7, D and E). Neither strain experienced the dramatic muscle injury observed in $\mathrm{B} / \mathrm{c}$ mice, evidenced by qualitative $\mathrm{H} \& \mathrm{E}$ staining and quantitative assessment of EBD and dystrophin immunostaining in the gastrocnemius (Figure 7, F, G, and I, and Supplemental Figure S9). In addition, force production was achieved in isolated extensor digitorum longus muscle from 129S mice that was matched with the control limb, further indicating that ischemia was incomplete in these mice (Figure $7 \mathrm{H}$ ). A/J extensor digitorum longus muscles did not produce force.

\section{Discussion}

$\mathrm{B} / \mathrm{c}$ mice experience persistent functional myopathy after subacute limb ischemia, despite both strains undergoing a matched partial reduction in blood flow. ${ }^{13,33}$ These observations led us to hypothesize that the $\mathrm{B} / \mathrm{c}$ parental background may harbor a greater inherent sensitivity to acute ischemic muscle injury. Herein, we tested this hypothesis by assessing muscle function and morphology during the myodegenerative phase of acute ischemia before significant vessel collateralization, immune responses, and myoregenerative processes were able to occur. $\mathrm{B} / \mathrm{c}$ mice experienced severe injury, characterized by histomorphological aberrations, enhanced myofiber permeability, and loss of dystrophin-positive immunostaining. Isolated muscles from both strains after 6 hours of HLI were unable to contract with external electrical stimulus. Detailed analysis of hind limb perfusion indicated that residual flow was similar between strains, but differed in some measures by approximately $5 \%$ to $10 \%$ when adjusted for control limb values. To address potential contributions from the observed differences in residual perfusion, muscle histomorphological patterns and primary muscle cell viability were compared using both in vitro and in vivo models of ischemia that were designed to be independent of the effects of residual perfusion. In both models, significant differences between $\mathrm{C} 57$ and B/c mice were observed. The muscle functional and histomorphological response was also assessed to HLI in two additional mouse strains chosen for their B/c-like and C57-like preexisting vascular anatomy. Neither of these strains experienced the dramatic muscle injury observed in $\mathrm{B} / \mathrm{c}$ mice. Taken together, these data indicate that $\mathrm{B} / \mathrm{c}$ mice experience rapid ischemic skeletal muscle injury that cannot be explained by the degree of perfusion reduction alone. Our findings provide a foundation for future studies that may seek to better understand the contribution of genetic and environmental factors that influence the ischemic myodegenerative response, and how this critical phase of injury may affect the myoregenerative recovery timeline in both acute and chronic PAD.

The vast majority of studies using murine hind limb ischemia to model PAD have focused on the recovery processes that occur several days or weeks after the injury was induced. Differences in recovery between inbred strains at these late time points have been largely attributed to altered regenerative capacity (ie, adult myogenesis and/or neovascularization) of the limb tissues, but the degree of initial injury has been solely attributed to the perceived completeness of the ischemic insult. ${ }^{5,11,18}$ The perfusion recovery curves observed when comparing C57 with $\mathrm{B} / \mathrm{c}$ mice are consistent among independent studies and involve a slow, linear, and incomplete recovery in $\mathrm{B} / \mathrm{c}$ mice compared with a rapid, nonlinear, full recovery in C57 mice. ${ }^{11,13,17,33}$ Poor interarterial network connectivity has been described in the skeletal muscle, skin, intestinal, and pial circulation in $\mathrm{B} / \mathrm{c}$ mice and has also been used as a possible explanation for the observed differences in the perfusion recovery time course between these strains. ${ }^{18,20,38}$ A common interpretation of this observation is that C57 mice are better able to support postischemic residual flow, which then facilitates collateral arteriogenesis during recovery via shear stress-dependent mechanisms. ${ }^{5,16,17}$ A major limitation of this interpretation is that it assumes that the magnitude of injury depends solely on the degree of occlusive burden, but these two parameters have not been measured together at the onset of ischemia in any of the aforementioned studies. These data indicate that $\mathrm{B} / \mathrm{c}$ mice experience dramatic muscle injury within only 6 hours of ischemia, despite close similarity in the degree of occlusive burden. This suggests that the magnitude of early ischemic injury may have greater influence over the perfusion recovery timeline than previously thought.

Because the degree of occlusive burden is directly related to the magnitude of the injury stimulus in this model, several redundant measurements were made both at baseline and after induction of ischemia. Perfusion and hemodynamic differences were detected between the strains at baseline, with $\mathrm{B} / \mathrm{c}$ mice displaying delayed recovery during occlusive reactive hyperoxia and reduced perfusion in the plantar paw compared with C57 mice. Immediately after HLI, perfusion 
differences between strains were detected in both the plantar paw and the medial thigh; however, the effect sizes were only approximately $5 \%$ to $10 \%$ when normalized for the control limb perfusion in each strain. Notably, small effect sizes in blood flow differences immediately after HLI in these strains have been reported previously. ${ }^{5}$ After 6 hours of HLI, similarly small differences were observed in perfusion, but no measureable difference were seen in tissue oxygen saturation in any of the limb muscles assessed. Because perfusion measurements are only proportional to blood displacement in the limb, it is possible that these mice have baseline differences in hematocrit or myoglobin content, which might lead to similar measurements of tissue oxygenation despite slight divergence in perfusion attributable to enhanced oxygen-carrying capacity in $\mathrm{B} / \mathrm{c}$ mice.

Several changes in muscle histomorphology were noticed in both strains after HLI that were consistent with the development of early necrosis and were also characterized by apparent structural compromise, indicated by loss of sarcolemmal dystrophin staining and EBD uptake. ${ }^{37,39}$ All $\mathrm{B} / \mathrm{c}$ mice had dramatic tissue damage, but C57 mice experienced a bimodal distribution of injury after 6 hours of HLI, with some mice experiencing no signs of tissue damage. One possible explanation for this observation is that tissue damage assorts by the degree of perfusion reduction, which may occur as a result of anatomic variation in size or distribution of conducting arteries. ${ }^{20,40}$ The data did not support this conclusion; however, there was no apparent association between postischemic perfusion level and clinical score in either strain. Furthermore, no association was observed among the postischemic perfusion levels of C57 mice that were stratified post hoc by whether signs of muscle injury were present in histologic preparations. Taken together, we conclude that perfusion alone is likely not the sole determinant of muscle injury during HLI. Alternatively, it is well known that first familial generation $\left(F_{1}\right)$ crosses between $\mathrm{C} 57$ and $\mathrm{B} / \mathrm{c}$ mice produce offspring that have a pattern of ischemic injury recovery that is more similar to C57 mice, indicating that C57 mice may harbor a dominant protective allele(s)..$^{9,28,41,42}$ It is possible that reduced penetrance of the protective allele(s) because of variable gene expression or modifier loci may be responsible for the observed injury distribution in this study. ${ }^{43}$

We have previously described impairments in autophagic flux, mass recovery, and growth-related gene expression in myotubes differentiated from primary $\mathrm{B} / \mathrm{c}$ myogenic progenitor cells, after experimental HND, that were not observed in C57 cells under the same conditions. ${ }^{11,27}$ These findings indicate that muscle cell-specific processes differ in response to ischemia between the strains in a model that is independent of perfusion and immune response. In this study, we detected a small, but statistically significant, decrease in B/c myotube viability after 6 hours of HND compared with $\mathrm{C} 57$ myotubes. In addition to these in vitro experiments, the strain-dependent tissue response to ischemia was assessed in the complete absence of residual flow in vivo by euthanizing a cohort of mice by cervical dislocation and assessing muscle tissue morphology several hours postmortem. Because the ultimate cause of death in cervical dislocation is respiratory failure without chemical contamination of the tissues, this treatment may best allow comparing tissue outcomes between strains with confidence that no differences in postischemic residual flow were present. ${ }^{44} \mathrm{~A}$ trending difference in clinical scores and a statistically significant difference in the number of dystrophin-positive fibers were observed at 3 hours postmortem. However, after 6 hours, both strains had similar degrees of muscle injury and no dystrophin-positive fibers, with the exception of one C57 mouse. Loss of sarcolemmal dystrophin during ischemia has been well characterized in cardiac muscle, and it is positively correlated with the degree of ischemic damage after myocardial infarction. ${ }^{45-48}$ Together, these data indicate that there is an innate difference in the timing of muscle cell-specific injury between the strains, which likely has dramatic effects on overall tissue resilience to ischemia when coupled with small differences in residual flow.

The driving forces of tissue necrosis during ischemia are complex and vary widely in different tissues and cell types, depending on the baseline dependence on oxidative metabolism and the ability to mount a stress response during prolonged hypoxia. ${ }^{31,49} \mathrm{~B} / \mathrm{c}$ and $\mathrm{C} 57$ primary myotubes do not differ in their ability to mount a hypoxic response through the hypoxia-inducible factor pathway. ${ }^{11}$ However, $\mathrm{B} / \mathrm{c}$ mice are known to have reduced exercise capacity and low tolerance for hypobaric oxygen at high altitudes compared with C57 mice, suggesting that other pathways influence the B/c response to hypoxia. ${ }^{50,51}$ Skeletal muscle necrosis during ischemia is believed to result largely from increased cytosolic $\mathrm{Ca}^{2+}$, resulting in postischemic contraction and protease activation, both of which contribute to autolysis and degradation of dystrophin. ${ }^{31,48}$ Cytosolic calcium levels are known to increase with time in hypoxic skeletal muscle, and $\mathrm{B} / \mathrm{c}$ mice have been shown to have a higher basal sarcoplasmic reticulum $\mathrm{Ca}^{2+}$ leak in cardiac muscle, which may also occur in the skeletal muscle. ${ }^{52,53}$ In addition, $\mathrm{B} / \mathrm{c}$ mice may be sensitive to reperfusion injury, ${ }^{23}$ although the increases in perfusion between post-HLI and 6 hours observed in this study were negligible, suggesting that reperfusion injury is not a significant contributor. Together, these data highlight the need for future studies aimed at uncoupling the specific factors that contribute to muscle necrosis during terminal ischemia.

Genome-wide association studies have been performed using these and other strains of mice to uncover potential genetic targets of susceptibility and resistance to ischemia. ${ }^{9,10,41,42}$ Follow-up studies have used this information to assess HLI responses in B/c mice expressing C57 gene variants identified by these genome-wide association studies; they have found that expression of several C57 variants has significant effects on HLI outcomes, including enhanced number/diameter of preexisting collateral arteries 
in the hind limb, ${ }^{28}$ improved postischemic perfusion recovery, ${ }^{10}$ and augmented ischemic myoregeneration. ${ }^{27}$ However, the aforementioned studies focused on tissue assessments that were made only during the myoregenerative phases and identified genes that are typically associated with late-stage processes in the injury recovery timeline, such as connective tissue remodeling, ${ }^{10}$ mature muscle homeostasis, ${ }^{27}$ and mechanotransduction. ${ }^{54}$

Although detailed comparison of the genetic contributions to the observed sensitivity of $\mathrm{B} / \mathrm{c}$ muscle to ischemic injury was outside the scope of this study, we wanted to investigate the possibility that additional inbred strains of mice that share a close common ancestor with either $\mathrm{B} / \mathrm{c}$ or C57 mice would have similar phenotypes under the same conditions. A/J mice (Bagg albino derivatives) were chosen as a B/c-like comparison, and 129S (Castle's mice) were chosen as a C57-like comparison. ${ }^{55}$ Interestingly, these mice have also been noted for having preexisting hind limb and cerebral collateral networks that are similar in form to their respective relatives. ${ }^{28,42} \mathrm{~A} / \mathrm{J}$ mice experienced a degree of perfusion reduction that was similar to $\mathrm{B} / \mathrm{c}$ mice, but surprisingly they did not develop the same degree of ischemic muscle injury. 129S mice did not experience the same degree of perfusion reduction as the other mouse strains tested, despite using an identical anatomic site of ligation/transection. Perhaps unsurprisingly, these mice did not incur significant muscle damage as a result of ischemia, although some injury was present. These data provide further support for the notion that additional factors, other than completeness of ischemia alone, can influence the magnitude of ischemic muscle injury.

Morbidity and mortality associated with PAD has continued to increase globally during the past several decades despite the number of lower extremity vascular procedures having doubled during that time. ${ }^{56,57}$ Recently, the field has begun to embrace the complex etiology of PAD, particularly the role of genetic determinants in chronic limb pathology. ${ }^{58,59}$ However, with regard to acute limb ischemia, the degree of pathology is universally attributed to the completeness of perfusion reduction, and little is known about critical determinants of tissue sensitivity to initial ischemic injury. ${ }^{3}$ This study provides evidence to suggest that genetic background may be one such critical determinant, which will lay a foundation for future studies that aim to investigate mechanistic effectors. This is an important first step toward a better understanding of acute ischemic limb pathology that may have significant implications for the development of novel therapeutics for patient populations that routinely experience major amputations when current therapies fail. ${ }^{60}$

\section{Supplemental Data}

Supplemental material for this article can be found at https://doi.org/10.1016/j.ajpath.2018.01.008.

\section{References}

1. Hiatt WR, Armstrong EJ, Larson CJ, Brass EP: Pathogenesis of the limb manifestations and exercise limitations in peripheral artery disease. Circ Res 2015, 116:1527-1539

2. Brass EP, Hiatt WR: Acquired skeletal muscle metabolic myopathy in atherosclerotic peripheral arterial disease. Vasc Med 2000, 5:55-59

3. Callum K, Bradbury A: $\mathrm{ABC}$ of arterial and venous disease: acute limb ischaemia. BMJ 2000, 320:764-767

4. Couffinhal T, Silver M, Zheng LP, Kearney M, Witzenbichler B, Isner JM: Mouse model of angiogenesis. Am J Pathol 1998, 152:1667-1679

5. Scholz D, Ziegelhoeffer T, Helisch A, Wagner S, Friedrich C, Podzuweit T, Schaper W: Contribution of arteriogenesis and angiogenesis to postocclusive hindlimb perfusion in mice. $\mathrm{J}$ Mol Cell Cardiol 2002, 34:775-787

6. Tang GL, Chang DS, Sarkar R, Wang R, Messina LM: The effect of gradual or acute arterial occlusion on skeletal muscle blood flow, arteriogenesis, and inflammation in rat hindlimb ischemia. J Vasc Surg 2005, 41:312-320

7. Kinnaird T, Burnett ES, Shou M, Lee CW, Barr S, Fuchs S, Epstein SE: Local delivery of marrow-derived stromal cells augments collateral perfusion through paracrine mechanisms. Circulation 2004, 109:1543-1549

8. Nakagami H, Maeda K, Morishita R, Iguchi S, Nishikawa T, Takami Y, Kikuchi Y, Saito Y, Tamai K, Ogihara T, Kaneda Y: Novel autologous cell therapy in ischemic limb disease through growth factor secretion by cultured adipose tissue-derived stromal cells. Arterioscler Thromb Vasc Biol 2005, 25:2542-2547

9. Dokun AO, Keum S, Hazarika S, Li Y, Lamonte GM, Wheeler F, Marchuk DA, Annex BH: A quantitative trait locus (LSq-1) on mouse chromosome 7 is linked to the absence of tissue loss after surgical hindlimb ischemia. Circulation 2008, 117:1207-1215

10. Dokun AO, Chen L, Okutsu M, Farber CR, Hazarika S, Jones WS, Craig D, Marchuk DA, Lye RJ, Shah SH, Annex BH: ADAM12: a genetic modifier of pre-clinical peripheral arterial disease. Am J Physiol Heart Circ Physiol 2015, 309:H790-H803

11. McClung JM, McCord TJ, Keum S, Johnson S, Annex BH, Marchuk DA, Kontos CD: Skeletal muscle-specific genetic determinants contribute to the differential strain-dependent effects of hindlimb ischemia in mice. Am J Pathol 2012, 180:2156-2169

12. Ryan TE, Schmidt CA, Green TD, Spangenburg EE, Neufer PD, McClung JM: Targeted expression of catalase to mitochondria protects against ischemic myopathy in high-fat diet-fed mice. Diabetes 2016, 65:2553-2568

13. McClung JM, McCord TJ, Southerland K, Schmidt CA, Padgett ME, Ryan TE, Kontos CD: Subacute limb ischemia induces skeletal muscle injury in genetically susceptible mice independent of vascular density. J Vasc Surg 2015, 64:1101-1111

14. Chu L-H, Vijay CG, Annex BH, Bader JS, Popel AS: PADPIN: protein-protein interaction networks of angiogenesis, arteriogenesis, and inflammation in peripheral arterial disease. Physiol Genomics 2015, 47:331-343

15. Ryan TE, Schmidt CA, Alleman RJ, Tsang AM, Green TD, Neufer PD, Brown DA, McClung JM: Mitochondrial therapy improves limb perfusion and myopathy following hindlimb ischemia. $\mathrm{J}$ Mol Cell Cardiol 2016, 97:191-196

16. Helisch A, Wagner S, Khan N, Drinane M, Wolfram S, Heil M, Ziegelhoeffer T, Brandt U, Pearlman JD, Swartz HM, Schaper W: Impact of mouse strain differences in innate hindlimb collateral vasculature. Arterioscler Thromb Vasc Biol 2006, 26:520-526

17. Chalothorn D, Faber JE: Strain-dependent variation in collateral circulatory function in mouse hindlimb. Physiol Genomics 2010, 42: 469-479

18. Chalothorn D, Clayton JA, Zhang H, Pomp D, Faber JE: Collateral density, remodeling, and VEGF-A expression differ widely between mouse strains. Physiol Genomics 2007, 30:179-191 
19. Zbinden S, Clavijo LC, Kantor B, Morsli H, Cortes GA, Andrews JA, Jang GJ, Burnett MS, Epstein SE: Interanimal variability in preexisting collaterals is a major factor determining outcome in experimental angiogenesis trials. Am J Physiol Heart Circ Physiol 2007, 292:H1891-H1897

20. Mac Gabhann F, Peirce SM: Collateral capillary arterialization following arteriolar ligation in murine skeletal muscle. Microcirculation 2010, 17:333-347

21. Imoukhuede PI, Popel AS: Expression of VEGF receptors on endothelial cells in mouse skeletal muscle. PLoS One 2012, 7:e44791

22. Cunha FF, Martins L, Martin PKM, Stilhano RS, Han SW: A comparison of the reparative and angiogenic properties of mesenchymal stem cells derived from the bone marrow of BALB/c and C57/BL6 mice in a model of limb ischemia. Stem Cell Res Ther 2013, 4:86

23. Carter WO, Bull C, Bortolon E, Yang L, Jesmok GJ, Gundel RH: A murine skeletal muscle ischemia-reperfusion injury model: differential pathology in BALB/c and DBA/2N mice. J Appl Physiol 1998, 85:1676-1683

24. van Weel V, Toes REM, Seghers L, Deckers MML, de Vries MR, Eilers PH, Sipkens J, Schepers A, Eefting D, van Hinsbergh VWM, van Bockel JH, Quax PHA: Natural killer cells and CD4+ T-cells modulate collateral artery development. Arterioscler Thromb Vasc Biol 2007, 27:2310-2318

25. Renault M-A, Chapouly C, Yao Q, Larrieu-Lahargue F, Vandierdonck S, Reynaud A, Petit M, Jaspard-Vinassa B, Belloc I, Traiffort E, Ruat M, Duplàa C, Couffinhal T, Desgranges C, Gadeau A-P: Desert hedgehog promotes ischemia-induced angiogenesis by ensuring peripheral nerve survival. Circ Res 2013, 112: 762-770

26. Sellers RS, Clifford CB, Treuting PM, Brayton C: Immunological variation between inbred laboratory mouse strains: points to consider in phenotyping genetically immunomodified mice. Vet Pathol 2012, 49:32-43

27. McClung JM, McCord TJ, Ryan TE, Schmidt CA, Green TD, Southerland KW, Reinardy JL, Mueller SB, Venkatraman TN, Lascola CD, Keum S, Marchuk DA, Spangenburg EE, Dokun AO, Annex BH, Kontos CD: A BAG3 coding variant in mice determines susceptibility to ischemic limb muscle myopathy by directing autophagy. Circulation 2017, 136:281-296

28. Sealock R, Zhang H, Lucitti JL, Moore SM, Faber JE: Congenic finemapping identifies a major causal locus for variation in the native collateral circulation and ischemic injury in brain and lower extremity. Circ Res 2014, 114:660-671

29. Paoni NF, Peale F, Wang F, Errett-Baroncini C, Steinmetz H, Toy K, Bai W, Williams PM, Bunting S, Gerritsen ME, Powell-Braxton L: Time course of skeletal muscle repair and gene expression following acute hind limb ischemia in mice. Physiol Genomics 2002, 11: 263-272

30. Chargé SBP, Rudnicki MA: Cellular and molecular regulation of muscle regeneration. Physiol Rev 2004, 84:209-238

31. Paradis S, Charles A-LA, Meyer A, Lejay A, Scholey JW, Chakfé N, Zoll J, Geny B: Chronology of mitochondrial and cellular events during skeletal muscle ischemia-reperfusion. Am J Physiol Cell Physiol 2016, 310:C968-C982

32. Mofarrahi M, McClung JM, Kontos CD, Davis EC, Tappuni B Moroz N, Pickett AE, Huck L, Harel S, Danialou G, Hussain SN: Angiopoietin-1 enhances skeletal muscle regeneration in mice. Am J Physiol Regul Integr Comp Physiol 2015, 308:R576-R589

33. Schmidt CA, Ryan TE, Lin C-T, Inigo MMR, Green TD, Brault JJ, Spangenburg EE, McClung JM: Diminished force production and mitochondrial respiratory deficits are strain-dependent myopathies of subacute limb ischemia. J Vasc Surg 2017, 65:1504-1514

34. Committee for the Update of the Guide for the Care and Use of Laboratory AnimalsNational Research Council: Guide for the Care and Use of Laboratory Animals: Eighth Edition. Washington, DC, National Academies Press, 2011
35. Schneider CA, Rasband WS, Eliceiri KW: NIH Image to ImageJ: 25 years of image analysis. Nat Methods 2012, 9:671-675

36. Spangenburg EE, Le Roith D, Ward CW, Bodine SC: A functional insulin-like growth factor receptor is not necessary for load-induced skeletal muscle hypertrophy. J Physiol 2008, 586: 283-291

37. Hamer PW, McGeachie JM, Davies MJ, Grounds MD: Evans blue dye as an in vivo marker of myofibre damage: optimising parameters for detecting initial myofibre membrane permeability. J Anat 2002, 200:69-79

38. Meisner JK, Sumer S, Murrell KP, Higgins TJ, Price RJ: Laser Speckle flowmetry method for measuring spatial and temporal hemodynamic alterations throughout large microvascular networks. Microcirculation 2012, 19:619-631

39. Harman JW: A histological study of skeletal muscle in acute ischemia. Am J Pathol 1947, 23:551-565

40. Kochi T, Imai Y, Takeda A, Watanabe Y, Mori S, Tachi M: Characterization of the arterial anatomy of the murine hindlimb: functional role in the design and understanding of ischemia models. PLoS One 2013, 8:e84047

41. Wang S, Zhang H, Dai X, Sealock R, Faber JE: Genetic architecture underlying variation in extent and remodeling of the collateral circulation. Circ Res 2010, 107:558-568

42. Keum S, Marchuk DA: A locus mapping to mouse chromosome 7 determines infarct volume in a mouse model of ischemic stroke. Circ Cardiovasc Genet 2010, 2:591-598

43. Montagutelli X: Effect of the genetic background on the phenotype of mouse mutations. J Am Soc Nephrol 2000, 11:S101-S105

44. Leary S, Underwood W, Anthony R, Cartner S, Corey D, Grandin T, Greenacre C, Gwaltney-Brant S, McCrackin M, Meyer R, Miller D, Shearer J, Yanong R: AVMA Guidelines for the Euthanasia of Animals: 2013 Edition. Edited by Golab G, Patterson-Kane E. Schaumburg, IL: American Veterinary Medical Association; 2013.

45. Kawada T, Masui F, Tezuka A, Ebisawa T, Kumagai H, Nakazawa M, Toyo-Oka T: A novel scheme of dystrophin disruption for the progression of advanced heart failure. Biochim Biophys Acta 2005, 1751:73-81

46. Kido M, Otani H, Kyoi S, Sumida T, Fujiwara H, Okada T, Imamura $\mathrm{H}$, Su-mida $\mathrm{T}$ : Ischemic preconditioning-mediated restoration of membrane dystrophin during reperfusion correlates with protection against contraction-induced myocardial injury. Am J Physiol Heart Circ Physiol 2004, 287:H81-H90

47. Rodríguez M, Cai WJ, Kostin S, Lucchesi BR, Schaper J: Ischemia depletes dystrophin and inhibits protein synthesis in the canine heart: mechanisms of myocardial ischemic injury. J Mol Cell Cardiol 2005, 38:723-733

48. Armstrong SC, Latham CA, Shivell CL, Ganote CE: Ischemic loss of sarcolemmal dystrophin and spectrin: correlation with myocardial injury. J Mol Cell Cardiol 2001, 33:1165-1179

49. Kalogeris T, Baines CP, Krenz M, Korthuis RJ: Cell biology of ischemia/reperfusion injury. Int Rev Cell Mol Biol 2012, 298: 229-317

50. Lerman I, Harrison BC, Freeman K, Hewett TE, Allen DL, Robbins J, Leinwand LA: Genetic variability in forced and voluntary endurance exercise performance in seven inbred mouse strains. J Appl Physiol 2002, 92:2245-2255

51. Cramer NP, Xu X, Christensen C, Bierman A, Tankersley CG, Galdzicki Z: Strain variation in the adaptation of C57B16 and BALBc mice to chronic hypobaric hypoxia. Physiol Behav 2015, 143: $158-165$

52. Howlett RA, Hogan MC: Intracellular PO2 decreases with increasing stimulation frequency in contracting single Xenopus muscle fibers. J Appl Physiol 2001, 91:632-636

53. Shah AP, Siedlecka U, Gandhi A, Navaratnarajah M, Al-Saud SA, Yacoub MH, Terracciano CM: Genetic background affects function and intracellular calcium regulation of mouse hearts. Cardiovasc Res 2010, 87:683-693 
54. Keum S, Lee HK, Chu PL, Kan MJ, Huang MN, Gallione CJ, Gunn MD, Lo DC, Marchuk DA: Natural genetic variation of integrin alpha L (Itgal) modulates ischemic brain injury in stroke. PLoS Genet 2013, 9:e1003807

55. Petkov PM, Ding Y, Cassell MA, Zhang W, Wagner G, Sargent EE, Asquith S, Crew V, Johnson KA, Robinson P, Scott VE, Wiles MV: An efficient SNP system for mouse genome scanning and elucidating strain relationships. Genome Res 2004, 14:1806-1811

56. Sampson UK, Fowkes FG, McDermott MM, Criqui MH, Aboyans V, Norman PE, Forouzanfar MH, Naghavi M, Song Y, Harrell FE Jr, Denenberg JO, Mensah GA, Ezzati M, Murray C: Global and regional burden of death and disability from peripheral artery disease: 21 world regions, 1990 to 2010. Glob Heart 2014, 9:145-158.e21
57. Goodney PP, Beck AW, Nagle J, Welch HG, Zwolak RM: National trends in lower extremity bypass surgery, endovascular interventions, and major amputations. J Vasc Surg 2009, 50:54-60

58. Hamburg NM, Creager MA: Pathophysiology of intermittent claudication in peripheral artery disease. Circ J 2017, 81: 281-289

59. Kullo IJ, Leeper NJ: The genetic basis of peripheral arterial disease: current knowledge, challenges, and future directions. Circ Res 2015, 116:1551-1560

60. Norgren L, Hiatt WR, Dormandy JA, Nehler MR, Harris KA, Fowkes FGR: Inter-society consensus for the management of peripheral arterial disease (TASC II). Eur J Vasc Endovasc Surg 2007, 33:S1-S75 